Federal Reserve Bank of Minneapolis Research Department

\title{
Consumption Over the Life Cycle: How Different Is Housing?
}

\author{
Fang Yang* \\ Working Paper 635 \\ Revised August 2006
}

\begin{abstract}
Micro data over the life cycle shows two different patterns of consumption of housing and non-housing goods: the consumption profile of non-housing goods is hump-shaped while the consumption profile for housing first increases monotonically and then flattens out. These patterns hold true at each consumption quartile. This paper develops a quantitative, dynamic general equilibrium model of life cycle behavior, which generates consumption profiles consistent with the observed data. Borrowing constraints are essential in explaining the accumulation of housing assets early in life, while transaction costs are crucial in generating the slow downsizing of the housing assets later in life. The bequest motives play a role in determining total life time wealth, but not the housing profile.
\end{abstract}

Keywords: Consumption, Housing, Life Cycle, Wealth Distribution

JEL Classification: E21, H31, J14, R21

\footnotetext{
*Yang, Federal Reserve Bank of Minneapolis and University of Minnesota. I would like to thank Michele Boldrin, John Boyd, Marco Cagetti, V. V. Chari, Mariacristina De Nardi, Zvi Eckstein, Larry Jones and seminar participants at 2004 CESifo Venice Summer Institute, Federal Reserve Bank at Atlanta, 2005 Midwest Macroeconomics Meetings, 2005 SED meeting, Federal Reserve Bank at Minneapolis, Federal Reserve Bank at Chicago, University of Colorado-Boulder, Rutgers University, SUNY-Albany, University of Toronto, Indiana University, Purdue University, Bank of Canada, University of Hong Kong, Hong Kong University of Science and Technology, for helpful comments and suggestions. I am grateful to Michele Boldrin and Mariacristina De Nardi for numerous suggestions and continuous encouragement. Financial support from Gross Fellowship is gratefully acknowledged. All remaining errors are my own. The views expressed herein are those of the author and not necessarily those of the Federal Reserve Bank of Minneapolis or the Federal Reserve System.
} 


\section{Introduction}

Micro data shows two different patterns of consumption of housing and non-housing goods over the life cycle. Consumption expenditure of non-housing goods is hump-shaped over the life cycle: it starts low early in life, rises considerably around middle age, and then falls at more advanced ages. On the contrary, household holdings of the housing stock are not humpshaped: lifetime profile of housing stock is monotonically increasing and then rather flat. The different patterns of housing and non-housing consumption over the life cycle contradict a key prediction of the standard life cycle model without market frictions: the ratio of housing and non-housing consumption should not be age-dependent. That is to say, housing consumption should follow the same pattern as non-housing consumption.

These stylized facts of life cycle consumption motivate asking which modifications of the basic life cycle framework could produce the life cycle consumption profiles that more closely resemble the US life cycle consumption profiles. To answer this question, I construct a general equilibrium life cycle model of consumption and saving that explicitly models housing. Housing has a dual role: it directly provides utility, and it can be used as collateral. In my framework, households face several frictions: uninsurable labor income risk, lack of annuity market to insure against uncertain lifetime, borrowing constraints, and transaction costs for trading houses. Thus households save to self-insure against labor earning shocks and life-span risk, for retirement, to enjoy services from housing, and possibly to leave bequests to their children.

I show that a plausibly parameterized version of my model accounts well for the empirical findings. The interaction between housing (which can be used as collateral) and borrowing constraints leads to the accumulation of housing stock early in life, while transaction costs tend to slow the decline of the housing stock later in life. Households begin their economic lives without any housing stock. During the early part of their lives, because of the existence of borrowing constraints and the role of housing as a collateral, they build housing stock quickly and compromise on non-housing consumption. As households age, they start to decrease their non-housing consumption because their time preference is higher than the interest rate and mortality rates are increasing along the life cycle. The high transaction costs associated with trading houses prevent households from decreasing their housing stock quickly later in life.

I also investigate the quantitative relevance of transaction costs, borrowing constraints and bequest motives in determining this pattern. I find that while borrowing constraints are essential in explaining the accumulation of housing assets early in life, the existence of transaction costs is crucial in accounting for the slow downsizing of housing profile later in life. When choosing a new house, forward-looking households take into account future transaction costs. Thus consumption of housing service will be constant at a new level until it is worthwhile to incur the transaction costs again. Thus the home purchase decision 
is endogenously infrequent. The bequest motives play a role in determining total lifetime wealth, but not housing consumption.

The model is able to capture the life cycle wealth portfolio profiles. In the US, young households virtually own no liquid financial assets, but hold a major fraction of their wealth as housing. Later in life, households shift their portfolios to financial assets.

The benchmark model also matches the distribution of wealth, housing and financial wealth quite well. It also replicates the empirical finding that inequality in financial assets is much higher than housing. Households are allowed to borrow against housing so financial assets can be negative but the housing stock can not be. Also the return of housing, marginal utility of housing, is decreasing, while the return to financial assets, the interest rate, is constant. Thus housing as the fraction of net worth is decreasing.

Understanding the life cycle pattern of consumption and assets allocation behavior is crucial for policy analysis. Identifying a model capable of explaining the housing and nonhousing consumption decisions allows a better understanding of the effect of policy reforms. The house is the single largest expenditure made by consumers over their life time. The median household has a house which is valued about twice their annual income. Thus the abstraction from housing may bias the study of life cycle consumption and assets accumulation behavior.

The paper is organized as follows. In Section 2, I present some empirical results from the Consumer Expenditure Survey (CEX) and Survey of Consumer Finances (SCF) documenting households' consumption and asset accumulation over the life cycle. In Section 3, I present my model and define the equilibrium. The calibration of the model is presented in Section 4 . Section 5 presents the quantitative results of the benchmark model. Section 6 investigates the quantitative importance of the transaction costs, bequest motives, borrowing constraints and social security. Brief concluding remarks are provided in Section 7. Technical discussions about the definition of stationary equilibrium, invariant distribution and bequest distribution, the calibration of aggregate variables and the computational algorithm are provided in the appendix.

\subsection{Contribution with respect to the literature}

Several mechanisms have been offered in the literature to study the hump-shaped life cycle consumption profile, such as, precautionary saving and borrowing constraints (Carroll and Summers (1991), Hubbard, Skinner and Zeldes (1994), Carroll (1997), Gourinchas and Parker (2002)), variations in household size (Attanasio and Weber (1995), Attanasio et al. (1999) and Browning and Ejrnæs (2002)), the substitutability of leisure and consumption (Bullard and Feigenbaum (2004)), and mortality risk (Hansen and Imrohoroglu (2005)). None of them incorporate housing. Among the literature that study life cycle consumption profile of durable goods, Fernandez-Villaverde and Krueger (2002) document that consumption expenditure is hump-shaped over the life cycle and this pattern holds for consumption expenditures on both 
non-durables and durables, even after controlling for the demographic characteristics of the households. Fernandez-Villaverde and Krueger (2001) show that a plausibly parameterized version of the life cycle model with endogenous borrowing constraints can explain the pattern of durable and nondurable consumption expenditure. However, their model cannot generate the slow decline of the housing stock. Heathcote (2002) incorporates home production in an otherwise standard model to account for the drop of consumption at retirement.

There are several papers that exploit the idea that in the presence of collateralized loans, borrowing constraints distort the intratemporal allocation of resources between durables and non-durables (see, for example, Brugianini and Weber (1992), Chah et al. (1995), Alessie et al. (1997), Jappelli (1990), and Attanasio et al. (2000)). In contrast to the above literature that tests the empirical significance of borrowing constraint from the data, I impose borrowing constraints in the model in conjunction with the transaction costs and maintenanceremodeling option.

This paper is related to the strands of optimal portfolio choice in the presence of consumer durables, such as Grossman and Laroque (1990), Cocco (2000), Flavin and Yamashita (2002), Flavin and Nakagawa (2002), Campbell and Cocco (2003), and Yao and Zhang (2005), and Ortalo-Magne and Rady (2006). In contrast with most models of household portfolio choice that explicitly include the presence of durables, I model housing in a general equilibrium setting.

Among the literature on life cycle general equilibrium models that incorporate bequest motives, De Nardi (2004) constructs a model in which parents and children are linked by accidental and voluntary bequests and by earning ability and shows that voluntary bequests can explain the emergence of large estates and the long upper tail of the wealth distribution. I generalize her framework by modeling housing and transaction costs. Ocampo and Yuki (2002) use a similar framework to investigate the quantitative importance of different saving motives on wealth inequality and aggregate capital accumulation. Laitner (2001) uses an overlapping generations model with both life cycle saving and altruistic bequest to match the high degree of wealth concentration and analyzes the impact of changes in national debt and social security on capital output ratio.

\section{Empirical Findings}

This section presents my empirical findings on consumption of non-housing and housing over the life cycle. I first study the life cycle profile of consumption of non-housing goods using data from the CEX. I deal explicitly with the changes of household size along the life cycle. Then I look at the life cycle profile of the net worth, housing stock and financial assets derived from the SCF, controlling for cohort and time effects.

The CEX is carried out by the Bureau of Labor Statistics, and is a random sample rotating panel that contains information on demographic characteristics, inventory of major 
housing and consumption expenditure. The survey consists of a quarterly Interview Survey in which each consumer unit in the sample is interviewed every three months over a 15month period, and a Diary Survey which is completed by the sample consumer units for two consecutive one-week periods. The Interview Survey is designed to collect data on major items of expense, household characteristics, and income. The expenditures covered by the survey are those that respondents can recall fairly accurately for three months or longer. The CEX is the only micro-level data set reporting comprehensive measures of consumption expenditure for a large cross-section of households in the US.

I use the 2001 CEX data to estimate life cycle profile of non-housing consumption expenditures $^{1}$. I take each household as one observation and use the age of the reference person regardless of the person's gender. I define 10 cohorts with a length of 5 years, starting from age 20. Only households with positive consumption expenditure are selected. The data on "expenditure on non-housing consumption" include food, alcoholic beverages, tobacco, personal care, utilities, household operations, household furnishings and equipment, transportation, books and electronic equipment, apparel, out-of-pocket health expenditure, entertainment and miscellaneous expenditures.

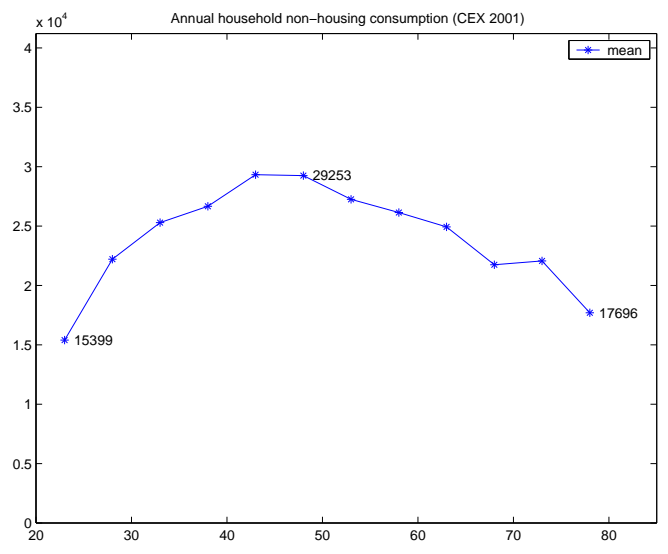

Figure 1: Non-housing consumption

Figure 1 plots total household annual expenditure on non-housing goods against the head of the household's age. Estimated consumption increases from around $\$ 15,400$ to nearly $\$ 29,300$, and then decreases to about $\$ 17,700$. The peak is reached at age forty-five. The size of the hump, measured by the ratio of consumption expenditure between the peak and the beginning of the life cycle, is around 1.9. The consumption expenditure on non-housing goods declines dramatically later in life. The pattern of non-housing consumption is similar to the pattern of nondurable consumption reported in Fernandez-Villaverde and Krueger (2002).

\footnotetext{
${ }^{1}$ Fernandez-Villaverde and Krueger (2002) use the CEX data to construct a pseudo panel. They find that the results from using pseudo panel and controlling for cohort and time effects is similar to results from using cross-section data. For simplicity I thus use only the 2001 CEX data.
} 


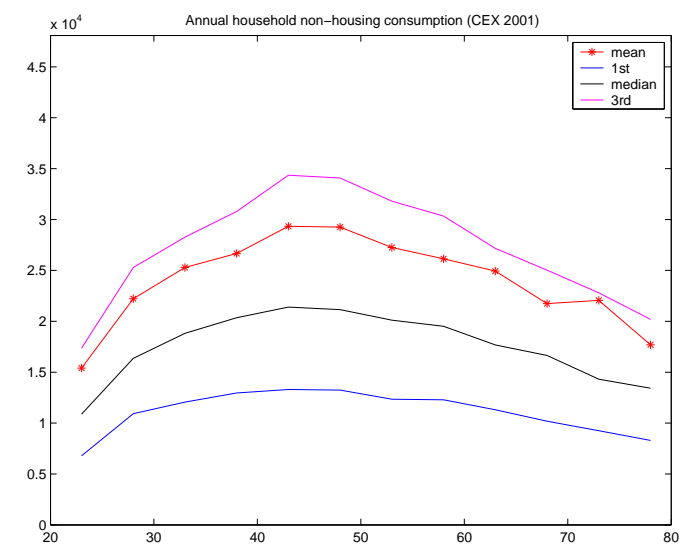

Figure 2: Non-housing consumption (quartiles)

If we go beyond mean consumption and look at the distribution of consumption, the hump-shaped non-housing consumption pattern still holds. For example, Figure 2 plots total household expenditure on non-housing goods at the mean level and at each quartile. We observe that the non-housing consumption is hump-shaped at each quartile. We also see that mean consumption is higher than the median, and lower than the 3rd quartile at each age. This indicates that the distribution of consumption at each age is skewed to the right.

Households of different size plausibly face different marginal utilities from the same consumption expenditure. Consequently, changes in household size might explain the hump in consumption (Attanasio and Weber (1995) and Attanasio et al. (1999)). Thus I adjust the data for the change in household size along the life cycle using equivalence scales, which quantify the change in consumption expenditure needed to keep the welfare of families constant, regardless of its size (see for example Zeldes (1989), Blundell, Browning and Meghir (1994)). I use the same equivalence scales as Fernandez-Villaverde and Krueger (2002), which are close to the equivalence scales of the Department of Health and Human Services (Federal Register (1991)), the estimates of Johnson and Garner (1995) and to the constant-elasticity equivalence scales used by Atkinson et al. (1995), Buhmann et al. (1988) and Johnson and Smeeding (1998), among others. Table 1 shows the equivalence scales I use.

\begin{tabular}{|l|l|l|l|l|l|}
\hline Family Size & 1 & 2 & 3 & 4 & 5 \\
\hline Equivalence scales & 1 & 1.34 & 1.65 & 1.97 & 2.27 \\
\hline
\end{tabular}

Table 1: Equivalence scales

I take non-housing consumption expenditure from the CEX and the demographic information of the household, and adjust consumption using the above equivalence scales. Figure 3 plots the estimated adjusted life cycle profile of adult-equivalent expenditure on non-housing goods. The adjusted consumption increases from around $\$ 12,000$ to nearly $\$ 18,900$ and then 
decreases to about $\$ 14,400$. The peak in adjusted consumption is postponed to age fiftyfive. The size of the hump, measured by the ratio of consumption expenditure between the peak and the beginning of the life cycle, is around 1.6. The consumption expenditure on non-housing goods declines dramatically later in life. We observe that the non-housing consumption is hump-shaped at each quartile. We also see that the distribution of consumption at each age is skewed to the right. The results are robust to using different equivalence scales.

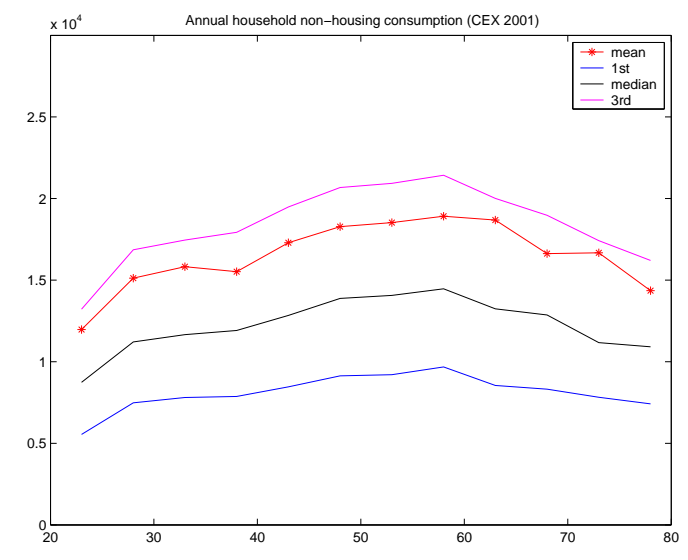

Figure 3: Non-housing consumption (adult equivalent)

I then use the SCF data to estimate the life cycle profile of housing stock, net worth and non-housing assets controlling for cohort and time effects. I construct synthetic cohorts by using six waves of the SCF (1983-1998). I use the age of the reference person to define 10 cohorts with a length of 5 years, starting from age 20, and follow them through the whole sample, generating a panel. For example, the households born between 1958-1963 were 20-25 years old in 1983. The pseudo panel approach treats the $23-28$ year-old households in the 1986 wave as if they were the same people as the 20-25 year-old in the 1983 data. The grouping in cells is done to keep the number of observations relatively big, and most of the cells I use have about 300 observations. Housing, net worth and non-housing assets are deflated to be in 1983 dollars using the CPI price index. Housing asset is the value of the primary residential house. Renters are also included in the sample. I control for cohort, time, and age effects by employing a semi-nonparametric partially linear model. Details of the estimation are available in Yang (2006).

Figure 4 plots the estimated housing stock over the life cycle from the SCF. The estimated housing value increases until age sixty-five, and then flattens out until the end of the life cycle. That is to say, if the service flow from housing is proportional to housing stock, then consumption from housing is not hump-shaped.

Figure 5 plots housing stock at the mean level and at each quartile. We observe that the housing consumption is increasing and then flattens out at each quartile. Also mean 


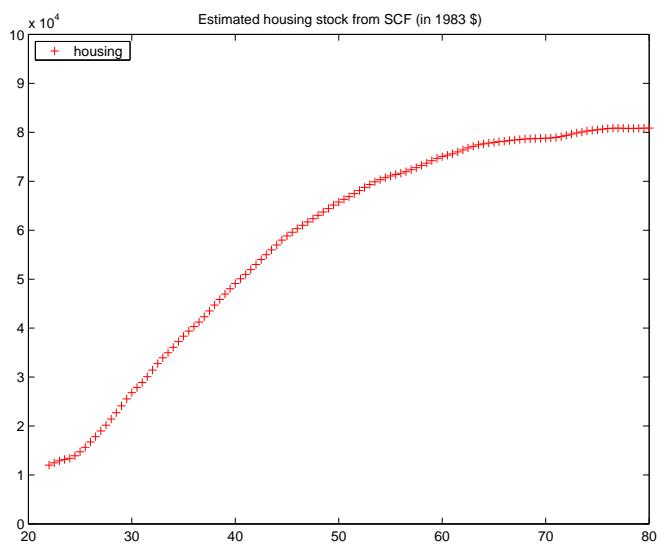

Figure 4: Housing consumption

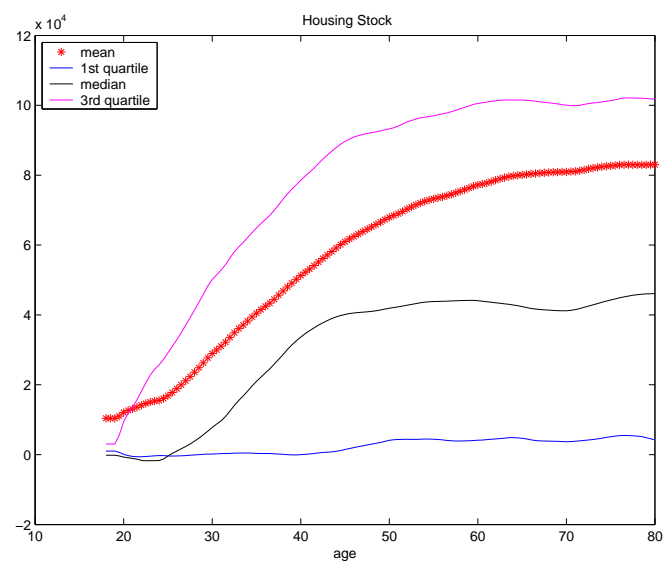

Figure 5: Housing consumption (quartiles)

consumption is higher than the median at each age, indicating that the distribution of housing consumption at each age is also skewed to the right.

The finding that elderly households do not decrease their housing consumption is consistent with the empirical findings from other literature. For example, Feinstein and McFadden (1989) suggest that more than one-third of elderly households reside in dwellings with at least three more rooms than the number of inhabitants, and are thus consuming large housing services. Fernandez-Villaverde and Krueger (2002) show that, when controlling for time and cohort effects, the peak of (market valued) housing service does not occur until age fifty-five, then decreases slightly, and then flattens out until the end of the life cycle.

To isolate the effect of homeownership on housing assets, I also estimate the profile of housing assets, for homeowners only. Figure 6 shows the smoothed age profile of housing assets, for homeowner only, for mean, 1st quartile, median and 3rd quartile. Compared with Figure 5, the profiles for homeowners have similar pattern as the profiles for homeowners and 


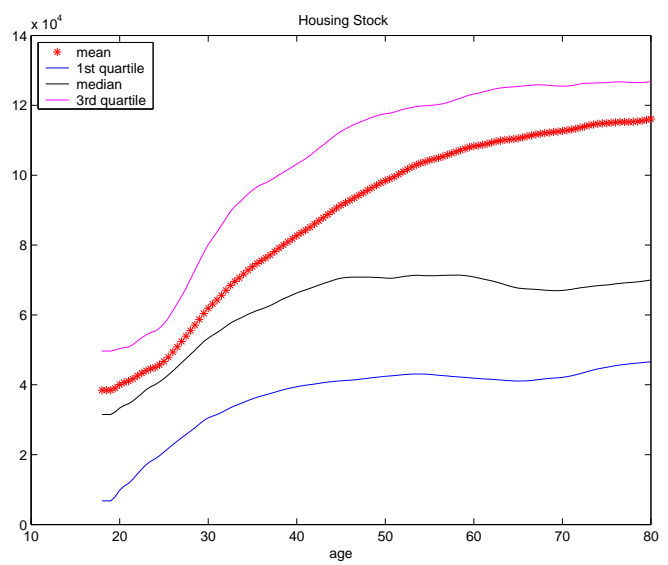

Figure 6: Housing consumption (owners)

renters together, but the levels are higher. This is simply because Figure 5 are estimated from samples containing renters who don't have any housing assets.

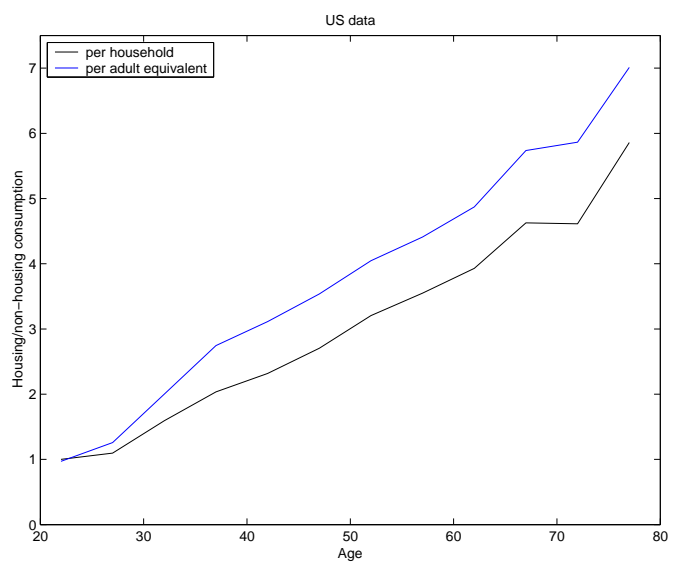

Figure 7: Ratio of housing to non-housing consumption

Figure 7 plots the ratio of housing to non-housing consumption, when I normalize the ratio at age 20 to be 1 . This ratio is increasing over the life cycle, reaching 5 (per household) and 7 (per adult equivalent) at age $75^{2}$.

The different patterns of housing and non-housing consumption over the life cycle thus contradict to a key prediction of the standard life cycle model without market frictions, age-dependent utility of consumption from housing and non-housing or home production: the ratio of housing and non-housing consumption should not be age-dependent. That is to say, consumption of housing should follow the same pattern as non-housing consumption.

\footnotetext{
${ }^{2}$ I do not adjust family size for housing consumption. Nelson (1988) finds that the economics of scale in shelter is so high that "two can live as cheap as one".
} 
Appendix 8.1 describes the implication of this standard life cycle model in greater detail.

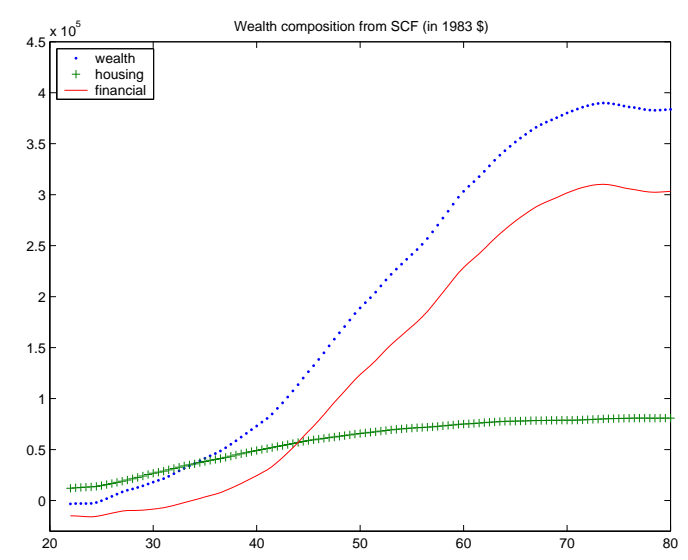

Figure 8: Age profile of wealth composition

I now show the patterns of wealth accumulation and portfolio composition over the life cycle. Figure 8 plots mean net worth, housing stock, financial assets against the head of the household's age. Young agents tend to hold little wealth. Early in life households borrow to buy houses, and thus save in the form of housing. As time goes by, agents have built stocks of houses and start to increase their holding of financial assets. The profiles of financial assets and housing assets intersect in their early 40's. Their wealth holding peaks at age 70 . However, we do not observe quick decumulation of wealth later in life. Instead, households continue to hold large amount of wealth.

\section{The Model}

The economy is a discrete-time overlapping generation world with an infinitely-lived government. The government taxes labor earnings, and provides pensions to the retirees. There are idiosyncratic income shocks. There are no state contingent markets for the household specific shocks. The only financial instrument is a one-period bond. Housing has a dual role: it provides utility as consumption goods, and it can be used as collateral thus the borrowing limit of each household depends on the value of the house. Trading of houses incurs transaction costs. For simplicity, I assume there is no housing rental market.

\subsection{Technology}

There is one type of goods produced according to the aggregate production function $F(K ; L)$ where $K$ is the aggregate capital stock and $L$ is the aggregate labor input. I assume a standard Cobb-Douglas functional form. The final goods can be either consumed or invested into physical capital or transformed into housing. Physical capital and housing depreciate at rate $\delta^{k}$ and $\delta^{h}$, respectively. Let $H$ denote the aggregate housing stock in the current period, 
$C$ the aggregate consumption of non-housing, $I^{h}$ the aggregate investment on housing, $I^{k}$ the aggregate investment on physical capital goods, $T c$ the total transaction costs for trading housing, respectively. The aggregate resource constraint is:

$$
F(K, L)=K^{\alpha} L^{1-\alpha}=C+I^{k}+I^{h}+T c .
$$

Households rent capital and efficient labor units to the representative firm each period and receive rental income at the interest rate $r$ and wage income at the wage rate $w$.

\subsection{Demographics}

During each model period, which is 5 years long, a continuum of people is born. I denote age $t=1$ as 20 years old, age $t=2$ as 25 years old, and so on. At age 20 each person enters into the model and start working and consuming. Since there are no inter-vivos transfers, all agents start their economic life with no financial assets and no houses. At the beginning of period 3, the agent's children are born, and four periods later (when the agent is 50 years old) the children are 20 and start working. The agents are retired at $t=10$ (i.e., when they are 65 years old) and die for sure by the end of age $T=12$ (i.e., before turning 80 years old). From $t=10$ (i.e., when they are 65 years old), each person faces a positive probability of dying given by $\left(1-p_{t}\right)$. The probability of dying is exogenous and independent of other household characteristics. The population grows at rate $n$. Since the demographic patterns are stable, agents at age $t$ make up a constant fraction of the population at any point in time. Figure 9 illustrates the demographics in the model.

\subsection{Timing and information}

At the beginning of each period, households observe their idiosyncratic earning shocks and possibly receive some inheritance from their parents. Then labor and capital are supplied to firms and production takes place. Next, the households receive factor payments and make their consumption and asset allocation decisions. Housing stocks are not transferred until the end of the period. Thus the addition or subtraction to the stock will not influence the present period service flow. Finally uncertainty about early death is revealed.

The idiosyncratic labor productivity status is private information and the survival status is public information. I assume that children can observe their parent's productivity when their parent is 50 and the children are 20.

\subsection{Consumer's maximization problem}

\subsubsection{Preferences}

Individuals derive utility from consumption of non-housing goods, $c$, from the service flow of the housing, $h$ and from bequests transferred to their children upon death. Preferences 


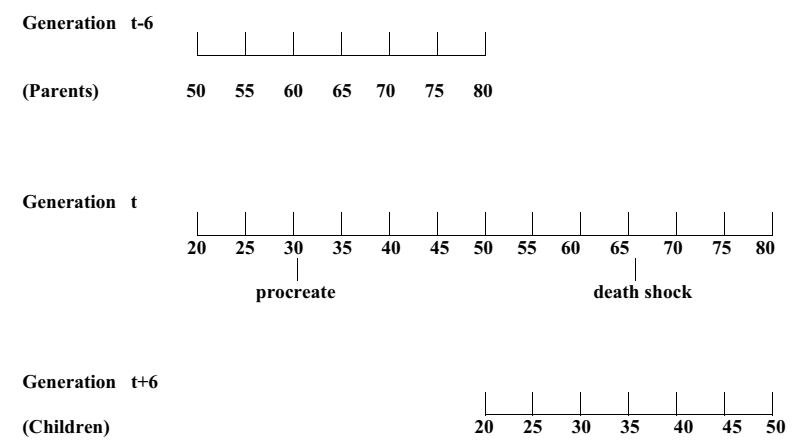

(Children)

Figure 9: Demographics

are assumed to be time separable, with a constant discount factor $\beta$. The momentary utility function from consumption is of the constant relative-risk aversion class given by

$$
U(c, h)=\frac{g(c, h)^{1-\eta}-1}{1-\eta} .
$$

I choose $g(c, h)=\left(\omega c^{\sigma}+(1-\omega) h^{\sigma}\right)^{\frac{1}{\sigma}}$, and $h$ is assumed to be equal to the value of housing stock.

Following De Nardi (2004), the utility from bequest is denoted by

$$
\phi(b)=\phi_{1}\left(1+b / \phi_{2}\right)^{1-\eta}
$$

The term $\phi_{1}$ reflects the parent's concern about leaving bequests to his/her children, while $\phi_{2}$ measures the extent to which bequests are luxury goods ${ }^{3}$.

\subsubsection{Transaction costs}

Due to the heterogeneity of housing and the spatial fixity of housing, both potential buyers and sellers in the housing market are forced to spend considerable amount of time and resource

\footnotetext{
${ }^{3}$ Note that this form of 'impure' bequest motives implies that an individual cares about the bequests left to his/her children, but not about consumption of his/her children. If an individual is assumed to care about utility of his/her children, and both parents and kids are maximizing utility as different units, the strategic interaction across generations complicates the analysis.
} 
to acquire information about the value of a specific housing units. As a consequence, there are both implicit and explicit search costs associated with moving (Chinloy (1980)). These include opportunity cost of time associated with market search, brokerage and agent fee, recording fee, legal fee, origination fee. Besides, households have to physically move to a new house, which entail moving costs and psychological costs of breaking neighborhood attachments (Smith, Rosen, Fallis (1988)).

I consider non-convex transaction costs in the housing stock. A household can buy a stock of any size, but once the stock has been bought, it is illiquid. I force the household to pay transaction costs every time the household sells and buys a new house. The specification of the transaction costs is:

$$
\tau\left(h, h^{\prime}\right)=\left\{\begin{array}{cc}
0 & \text { if } h^{\prime} \in\left[\left(1-\mu_{1}\right) h,\left(1+\mu_{2}\right) h\right] \\
\rho_{1} h+\rho_{2} h^{\prime} & \text { otherwise. }
\end{array}\right.
$$

This formulation of transaction costs allow households to change their level of housing consumption by undertaking housing renovation up to a fraction of $\mu_{2}$ the value of house or by allowing depreciation up to a fraction of $\mu_{1}$ the value of house as an alternative to moving. If the households let the housing depreciate by more that a fraction $\mu_{1}$ of the value, or if the value of the stock increases by more that a fraction $\mu_{2}$ of the value, I assume that the stock has been sold. In those cases, the household has to pay the transaction costs as a fraction $\rho_{1}$ of its selling value and $\rho_{2}$ of its buying value.

\subsubsection{Borrowing constraints}

I assume that only collateralized credit is available and that the borrowing interest rate, mortgage interest rate and deposit interest rate are all equal. This implies that mortgages and deposits are perfect substitutes. I use $a_{t}$ to denote the net asset position. To buy a house household must satisfy a minimum down payment requirement as a fraction $\theta$ of the value of house. Housings also serves as collateral for loans (through home equity loans or refinancing) up to a fraction $(1-\theta)$. At any given period household's financial assets must hence satisfy:

$$
a^{\prime} \geq-(1-\theta) h^{\prime}
$$

and household's net worth is thus always non-negative. Notice in this case, a household's net worth is bounded below by a fraction $\theta$ of the value of house ${ }^{4}$.

\footnotetext{
${ }^{4}$ For a household without a house, the borrowing constraint reduces to the standard form $a \geq 0$.
} 


\subsubsection{Labor productivity}

In this economy all agents of the same age face the same exogenous age-efficiency profile $\epsilon_{t}$. This profile is estimated from the data and recovers the fact that productive ability changes over the life cycle. Workers also face stochastic shocks to their productivity level. These shocks are represented by a Markov process defined on $(Y ; \mathfrak{B}(Y))$ and characterized by a transition function $Q_{y}$, where $Y \subset R_{++}$and $\mathfrak{B}(Y)$ is the Borel algebra on $Y$. This Markov process is the same for all households. This implies that there is no aggregate uncertainty over the aggregate labor endowment although there is uncertainty at the individual level. The total productivity of a worker of age $t$ is given by the product of the worker's stochastic productivity in that period and the worker's deterministic efficiency index at the same age: $y_{t} \epsilon_{t}$.

To capture the positive correlation in human capital across generations, I assume that the parent's productivity shock at age 50 is transmitted to children at age 20 according to a transition function $Q_{y h}$, defined on $(Y ; \mathfrak{B}(Y))$. What the children inherit is only their first draw; from age 20 on, their productivity $y_{t}$ evolves stochastically according to $Q_{y}$.

For computational reasons, I assume that children cannot observe directly their parent's assets, but only their parent's productivity when their parent is 50 and the children are 20, that is, the period when they leave the house and start working ${ }^{5}$. Based on this information, children infer the size of the bequests they are likely to receive.

\subsubsection{The household's recursive problem}

In the stationary equilibrium, the household's state variables are given by $(t, a, h, y, y p)$, the first 4 variables of which denote the agent's age, financial assets and housing stock carried from the previous period and the agent's productivity, respectively. The last term yp denotes the value of the agent's parent's productivity at age 50 until the agent inherits and zero thereafter. The law of motion of $y p$ is dictated by the death probability of the parent. When yp is positive, it is used to compute the probability distribution on bequests that the household expects from the parent. When the agents have already inherited, yp is set to be 0.

According to the demographic transitions, there are four cases.

(i) From $t=1$ to $t=3$ (from age 20 to 35 ), the agent survives with certainty until next period and does not expect to receive a bequest soon because his or her parent is younger than 65 . For these sub periods $y p^{\prime}=y p$.

$$
V(t, a, h, y, y p)=\max _{c, a^{\prime}, h^{\prime}}\left\{U(c, h)+\beta E\left(V\left(t+1, a^{\prime}, h^{\prime}, y^{\prime}, y p\right)\right)\right\}
$$

\footnotetext{
${ }^{5}$ For example, allowing children to observe parents productivity at two periods adds one more state variable and also increases substantially the time needed to iterate over the bequest distributions. Since income in the calibration is very persistent, an observation of one year of income is likely to be not much less informative than two.
} 
subject to (5) and

$$
\begin{aligned}
c+a^{\prime}+h^{\prime}+\tau\left(h^{\prime}, h\right) & =\left(1-\tau_{l}\right) w \epsilon+(1+r) a+\left(1-\delta^{h}\right) h, \\
c & \geq 0, h^{\prime} \geq 0 .
\end{aligned}
$$

At any subperiod, the agent's resources are derived from asset holdings, $a$, labor endowment, $\epsilon_{t} y$ housing stock holding, $h$. Asset holdings pay a risk-free rate $r$ and labor receives a real wage $w$. Houses depreciate at rate $\delta^{h}$. The evolution of $y$ is described by the transition function $Q_{y}$. Government taxes labor income at the rate $\tau_{l}$.

(ii) From $t=4$ to $t=6$ (from age 35 to 50 ), the worker survives for sure until the next period. However, the agent's parent is at least 65 years old and faces a positive probability of dying at any period; hence, a bequest might be received at the beginning of the next period. The conditional distribution of bequest a person of state $x$ expects in case of parental death is denoted by $\mu_{b}(x ;:)$. In equilibrium this distribution must be consistent with the parent's behavior. Since the evolution of the state variable $y p$ is dictated by the death process of the parent, $y p^{\prime}$ jumps to zero with probability $1-p_{t+6}$. Let $I_{y p>0}$ be the indicator function for $y p>0$; it is one if $y p>0$ and zero otherwise.

$$
V(t, a, h, y, y p)=\max _{c, \widetilde{a}, h^{\prime}}\left\{U(c, h)+\beta E\left(V\left(t+1, a^{\prime}, h^{\prime}, y^{\prime}, y p^{\prime}\right)\right)\right\}
$$

subject to (5), (8), and

$$
\begin{aligned}
c+\widetilde{a}+h^{\prime}+\tau\left(h^{\prime}, h\right) & =\left(1-\tau_{l}\right) w \epsilon+(1+r) a+\left(1-\delta^{h}\right) h, \\
a^{\prime} & =\widetilde{a}+b^{\prime} I_{y p>0} I_{y p^{\prime}=0},
\end{aligned}
$$

where $\widetilde{a}$ denotes the financial assets at the end of the period before receiving bequest.

(iii) The subperiods $t=7$ to $t=9$ (from age 50 to 65 ) is the periods before retirement, during which no more inheritances are expected because the agent's parent is already dead by that time. Thus yp is not in the state space any more. The agent does not face any survival uncertainty.

$$
V(t, a, h, y)=\max _{c, a^{\prime}, h^{\prime}}\left\{U(c, h)+\beta E\left(V\left(t+1, a^{\prime}, h^{\prime}, y^{\prime}\right)\right)\right\}
$$

subject to (5), (7) and (8).

(iv) From $t=10$ to $t=12$ (from age 65 to 80 ), the agent does not work and does not inherit any more, but faces a positive probability of dying. Let $p_{t}$ denote the conditional survival probability at age $t$. In case of death, the agent derives utility from bequeathing his or her assets. When the agent dies, the house is sold automatically and transaction costs are 
incurred ${ }^{6}$.

$$
V(t, a, h)=\max _{c, a^{\prime}, h^{\prime}}\left\{U(c, h)+\beta p_{t}\left(V\left(t+1, a^{\prime}, h^{\prime}\right)\right)+\left(1-p_{t}\right) \phi(b)\right\}
$$

subject to (5), (8) and

$$
\begin{gathered}
c+a^{\prime}+h^{\prime}+\tau\left(h^{\prime}, h\right)=(1+r) a+\left(1-\delta^{h}\right) h+P, \\
b=a^{\prime}+h^{\prime}-\tau\left(h^{\prime}, 0\right) .
\end{gathered}
$$

Households receive pension income $P$. For simplicity, I assume the pension level is independent of household's income history ${ }^{7}$.

\section{Calibration}

I choose some parameters used in the benchmark model from estimations by other studies. The remaining parameters are chosen so that the model generated data match a given set of targets. Since one period in my model corresponds to 5 years in real life, I adjust parameters accordingly.

The rate of population growth, $n$, is set to the average population growth from 1950 to 1997 from Economic Report of the President (1998). The $p_{t}$ 's are the vectors of conditional survival probabilities for people older than 65. I use the mortality probabilities of people born in 1965 provided by Bell, Wade, and Goss (1992).

I construct measures of output $Y$, capital $K$ and housing $H$ and their investment counterparts according to my model. I use data from the National Income and Product Accounts and the Fixed Assets Tables both from the Bureau of Economic Analysis for the year 19541999. The aggregate ratios for US economy are calibrated to explicitly consider the existence of housing that comprises residential assets. Output is defined as measured GDP minus housing services. Capital is defined as the sum of nonresidential private and government fixed assets plus the stock of inventories. Investment in capital, $I$ is defined accordingly. The housing stock is defined as the stock of private residential assets. Investment in housing, $I^{h}$, is constructed accordingly. The term $\alpha$ is the share of income that goes to capital, which I turns out to be 0.226 . This capital share (non residential stock of capital) is much lower than that in other calibrations, which abstract from housing. The rate $r$ is the interest rate on capital net of depreciation. I calibrate $\delta^{k}$ to be 0.0700 and $\delta^{h}$ to be 0.0294 . Given the calibration for the US production function, this interest rate is endogenous, and turns out to

\footnotetext{
${ }^{6}$ I made this simplification since the children already have houses of their own when they inherit.

${ }^{7} \mathrm{~A}$ more realistic assumption is that social security benefit is a concave function of the accumulated contribution. Under this assumption, the accumulated contribution becomes a state variable, which increases the computation time dramatically.
} 
be $4.37 \%$. Appendix 8.5 explains the rationale behind these choices in greater detail.

The deterministic age-profile of the unconditional mean of labor productivity, $\epsilon_{t}$, is taken from Hansen (1993). Since I impose mandatory retirement at the age of 65 , I take $\epsilon_{t}=0$ for $t>9$. The stochastic productivity process is assumed to be an $\mathrm{AR}(1)$ process:

$$
\ln y_{t}=\rho_{y} \ln y_{t-1}+\mu_{t} \quad \mu_{t} \backsim N\left(0, \sigma_{y}^{2}\right)
$$

The persistence $\rho_{y}$ and variance $\sigma_{y}^{2}$ are estimated from Panel Study on Income Dynamics (PSID) data, aggregated over five years in order to be consistent with the model period (Altonji and Villanueva (2002)). The parent's productivity shock at age 50 is transmitted to children at age 20 according to the following transition function:

$$
\ln y_{1}=\rho_{y h} \ln y_{h, 7}+\nu_{1}, \nu_{1} \sim N\left(0, \sigma_{y h}^{2}\right)
$$

I take $\rho_{y h}$ from Zimmerman (1992), and choose $\sigma_{y h}^{2}$ to match the Gini coefficient of 0.44 for earnings.

The down payment ratio $\theta$ is set to be 0.2 , which is commonly used in housing literature. Recently some households are allowed to purchase houses without much initial wealth. However, Caplin et al. (1997) argue that "it is almost impossible for a household to purchase a home without available liquid assets of at least $10 \%$ of the home's value". In addition, what is crucial for my model is the assumption that young and poor household can not borrow beyond the liquidation value of their collateral. Thus I choose a higher down payment ratio despite the recent decline of down payment ratio. I see the effect of down payment ratio in Section 6 .

Since one of my main interest is to look at how transaction costs affect consumption and saving decisions, one key calibration is the type of transaction costs that I choose. Smith, Rosen and Fallis (1988) estimate the transaction costs of changing houses, including searching, legal costs, cost of readjusting home, and psychological costs from disruption. Their estimation is approximately 8-10 percentage the unit being changed. Martin (2002) finds that the monetary costs of buying a new home, which include agent fee, transfer fee, appraisal and inspection fee, range on average from 7 to 11 percent of purchase price of a home. Gruber and Martin (2003) estimate the reallocation cost of tax and agency costs from CEX and find the median household pays costs of the order of 7 percent to sell their houses and 2.5 percent to purchase. In my simulation, I choose transaction costs from sale to be $\rho_{1}=6 \%$, and transaction costs from purchase to be $\rho_{2}=2 \%$. These values are lower than the transaction costs reported above therefore they serve as a lower bound of the effect of transaction costs. I set $\mu_{1}=\mu_{2}=0$. That is to say, if the value of the housing stock increases or decreases, I assume that the house has been sold.

The social security income $P$ is chosen to be $40 \%$ of the average household after tax earnings, a number commonly used in the social security literature. The labor income tax $\tau_{l}$ 
is chosen to balance government budget.

I take risk aversion parameter, $\eta$, to be 1.5, from Attanasio et al. (1999) and Gourinchas and Parker (2002), who estimate it from consumption data. This value is in the commonly used range (1-5) in the literature. $\sigma$ governs the elasticity of substitution between housing and non-housing. Ogaki and Reinhart (1998) use aggregate data and a similar specification, and obtain an estimated $\sigma=0.145$, not significantly different from zero. I thus choose $\sigma$ to be 0 so that the momentary utility function $g(c, h)$ takes the Cobb-Douglas form ${ }^{8}$. I see the effect of elasticity of substitution between housing and non-housing in Section 6 .

I choose the discount factor, $\beta$, to match the capital-output ratio. The parameter $\omega$ determines the share of consumption allocated to the non-housing consumption goods and is set to match the ratio of non-housing expenditure to housing stock. I use $\phi_{1}$ to match bequest output ratio of $2.65 \%$ in the US simulation (Gale and Scholz (1994)) ${ }^{9} \cdot \phi_{2}$ is chosen to match the ratio of average bequest left by single decedents at the lowest 80th percentile over average household earnings. According to Hurd and Smith (2001), the average bequest left by single decedents at the lowest 80th percentile was $\$ 125,000$ (Asset and Health Dynamics Among the Oldest Old (AHEAD) data sets, 1993-95).

\section{$5 \quad$ Numerical Results}

The benchmark economy allows for housing transaction costs and $\mu_{1}=\mu_{2}=0$. That is to say, if the value of the housing stock increases or decreases, I assume that the house has been sold. In this case, the household has to pay the transaction costs as a fraction $\rho_{1}=6 \%$ of its selling value and $\rho_{2}=2 \%$ of its buying value. Some parameters are set so that the model-generated data match a given set of targets (see Section 4). Appendix 8.6 describes the computation algorithm in greater detail.

\section{$5.1 \quad$ Life cycle profiles}

Now I show the average life cycle profiles of financial assets, total net worth, non-housing consumption and housing consumption. All figures are normalized by the average household earnings. These averages are obtained by integrating the policy function with respect to the equilibrium measure of agents, holding age fixed. For example, the average housing consumption by an agent at age $t$ is given by

$$
H=\frac{\int h(t, a, h, y, y p) m^{*}(\{t\} \times d a \times d h \times d y \times d y p)}{\int m^{*}(\{t\} \times d a \times d h \times d y \times d y p)}
$$

Figure 10 compares the average life cycle profiles of annual non-housing consumption and

\footnotetext{
${ }^{8}$ In this case I add a positive number $\varepsilon$ so that utility function is well defined at $h=0$. The term $\varepsilon$ is small enough that it does not affect the results. The utility function takes form $g(c, h)=c^{\omega}(h+\varepsilon)^{1-\omega}$

${ }^{9}$ Since in my model output corresponds to GDP minus housing service, I adjust it accordingly.
} 


\begin{tabular}{|c|l|c|}
\hline \multicolumn{2}{|l|}{ Parameters } & Calibrations \\
\hline \multicolumn{2}{|l|}{ Demographics } & $1.2 \%$ \\
\hline$n$ & population growth & see text \\
\hline$p_{t}$ & survival probability & 0.226 \\
\hline \multicolumn{2}{|l|}{ Technology } & 0.0700 \\
\hline$\alpha$ & capital share in National Income & 0.0294 \\
\hline$\delta^{k}$ & depreciation rate of capital & \\
\hline$\delta^{h}$ & depreciation rate of housing & see text \\
\hline Endowment & 0.85 \\
\hline$\epsilon_{t}$ & age-efficiency profile & 0.30 \\
\hline$\rho_{y}$ & AR(1) coefficient of income process & 0.677 \\
\hline$\sigma_{y}^{2}$ & innovation of income process & 0.37 \\
\hline$\rho_{y h}$ & AR(1) coefficient of income inheritance process & \\
\hline$\sigma_{y h}^{2}$ & innovation of income inheritance process & 8 \\
\hline Government policy & 0.07 \\
\hline$\tau_{l}$ & social security tax & 0.40 \\
\hline$P$ & social security replacement rate & 0.20 \\
\hline Housing market & $6 \%$ \\
\hline$\theta$ & down payment ratio & $2 \%$ \\
\hline$\rho_{1}$ & transaction costs of selling housing \\
\hline$\rho_{2}$ & transaction costs of buying housing & 0.8615 \\
\hline$\mu_{1}$ & Maximum depreciation & 0.946 \\
\hline$\mu_{2}$ & Maximum renovation & -17 \\
\hline Preference & \\
\hline$\eta$ & risk aversion coefficient & \\
\hline$\sigma$ & substitutability of housing and non-housing \\
\hline$\omega$ & weights of non-housing in utility function \\
\hline$\beta$ & discount factor & \\
\hline$\phi_{1}$ & weight of bequest in utility function \\
\hline$\phi_{2}$ & shifter of bequest in utility function \\
\hline
\end{tabular}

Table 2: Parameters used in the benchmark model 
housing consumption in the model with those in the data reported in Figure 3 and Figure 4. I adjust the data so that aggregate non-housing consumption is the same in the data as in the model ${ }^{10}$, and aggregate housing stock is the same in the data as in the model. From Figure 10, we see the hump shape of average non-housing consumption, which peaks at age 50's. The non-housing consumption at age 50 is $80 \%$ more than that of age 20 , which is similar to the pattern reported in the data. After the peak, non-housing consumption decreases steadily with age. The non-housing consumption at age 50 is $25 \%$ more than that of age 75 . Facing an increasing future income profile, young agents would like to borrow to finance their current consumption but they are borrowing constrained. This explains why early in life consumption path increases as income path does. As households age, they start to decrease their non-housing consumption due to the fact that time preference is higher than the interest rate and mortality rates are increasing along the life cycle. Compared with data, the non-housing consumption is lower between age 20-35. This may be due to the abstraction of inter-vivos transfers or housing rental market in the model. Inter-vivos transfer relaxes borrowing constraints, while a housing rental market allows young households to have high non-housing consumption while renting. For detailed discussions of the implications of those two limitations, see Section 7.

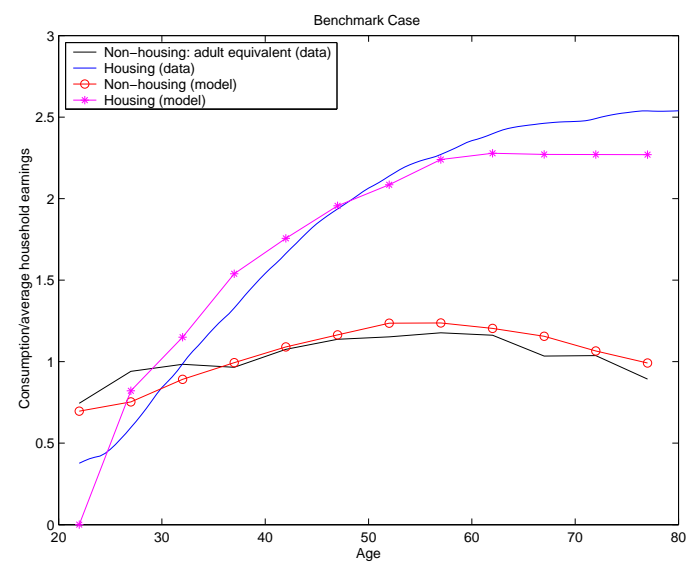

Figure 10: Life cycle patterns of consumption (benchmark)

The housing consumption profile in the model reproduces the empirically observed increasing early in life and slow downsizing later in life. Agents build their housing stock early in life and compromise on non-housing consumption. Agents build up their highest housing stock at the age of 60,5 years later than the peak of non-housing consumption. The elderly do not decrease their housing stock later in life.

The model also generate the pattern that the ratio of housing to non-housing consumption

\footnotetext{
${ }^{10}$ In the model I match the aggregate consumption with this in the NIPA. Compared with NIPA, CEX underreports consumption by a fraction of $30 \%$ (see Attanasio, Battistin and Ichimura (2004) for detailed discussion). Thus I adjust for the difference accordingly.
} 


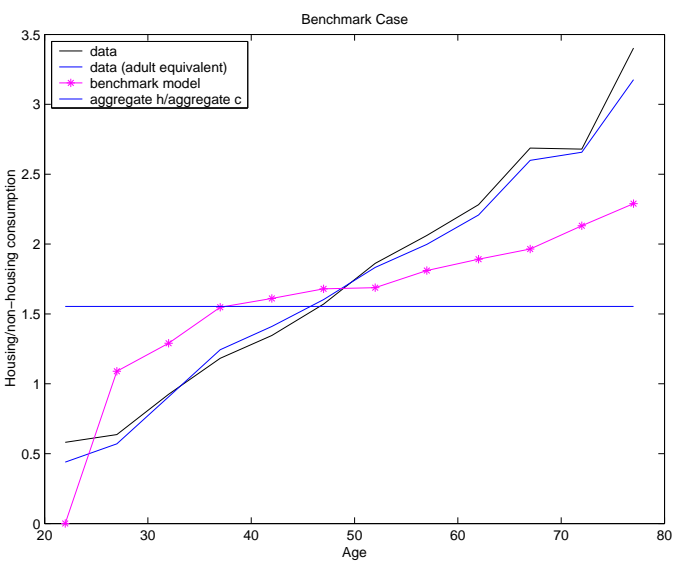

Figure 11: Ratio of housing to non-housing consumption (benchmark)

increases over the life-cycle. Figure 11 compares this ratio in the model and in the data. Early in life, the ratio of housing to non-housing is higher than that in the data. This is because in the model non-housing consumption is lower than that in the data. Later in life, the ratio of housing to non-housing is lower than that in the data. This is because in the model nonhousing consumption is higher than in the data. A parsimonious model without borrowing constraints and transaction costs in trading houses implies a constant ratio of housing to nonhousing consumption, which is equal to $\frac{H}{C}$. If we denote the difference in the ratio between the data and the parsimonious model without borrowing constraints and transaction costs in trading houses to be 1 , the model account for $60 \%$ of the difference.

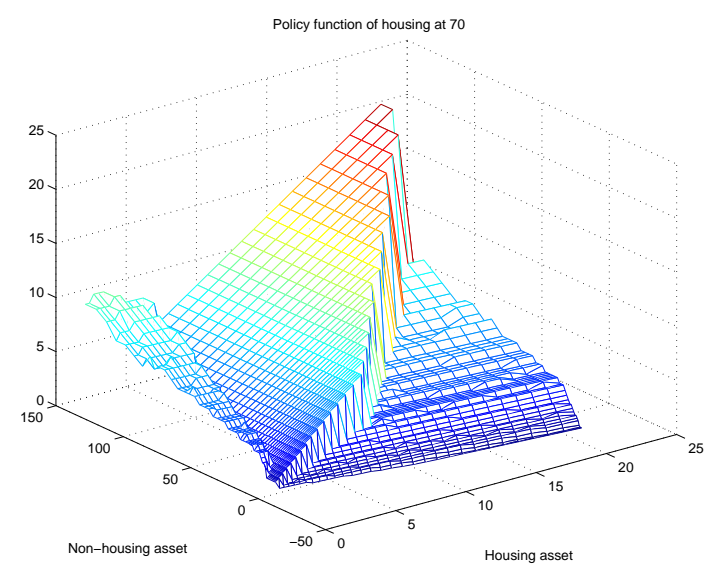

Figure 12: Policy function of housing stock next period for a 70-year-old

The introduction of transaction costs forces agents to reduce the frequency of transactions in the housing market. Agents make no change to the stock of the housing unless their nonhousing assets and housing stocks are too unbalanced. Two retired agents with the same housing stock, age and different holding of non-housing assets may choose the same level 
of housing stock next period, as long as the difference of non-housing assets is not large. Given current housing stock, there is a wide range of non-housing assets that households do not adjust for their housing stock. The size of the inactive region is different according to agents age and income and also is affected by parameters such as the size of the transaction costs. Figure 12 shows the policy function of housing next period as a function of current holding of non-housing and housing stock for a 70-year-old agent. Even for relatively small transaction costs, the inactive region is quite large. The inactive region can be defined by two boundaries, $\left(a_{l}(h), a_{h}(h)\right)$. If a household with a housing stock of $h$ holds non-housing assets more than the upper boundary $a_{h}(h)$, the household will move to a bigger house next period and hold a smaller fraction of non-housing assets in the wealth portfolio. If instead he/she holds non-housing assets less than the lower boundary $a_{l}(h)$, the household will move to a smaller house next period and hold a larger fraction of non-housing assets in the wealth portfolio. Figure 13 shows the boundaries of the inactive region on the plane of current holding of non-housing and housing stock for a 70-year-old agent and a 65-year-old agent, respectively. One reason that the inactive region for a 65 -year-old agent is smaller than a 70-year-old agent is because a 65-year-old agent has a longer life expectancy which increases the benefit of changing the housing stock. Since bequest is modeled as luxury goods, the utility function is not homothetic. Thus the policy functions are not necessarily homogeneous and the boundaries are not strict lines.

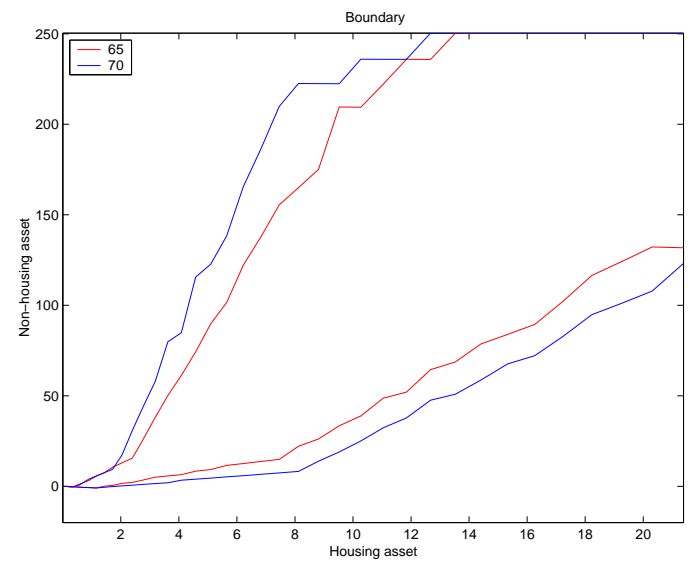

Figure 13: Boundaries of inactive zones

Now we go beyond mean consumption and look at the distribution of consumption in the benchmark economy. Figure 14 plots non-housing consumption at the mean level and at each quartile. We observe that the non-housing consumption is hump-shaped at each quartile. The benchmark economy also generates the skewed distribution of consumption at each age group, as is observed in the data.

Figure 15 plots housing consumption at the mean level and at each quartile. The benchmark economy generates the increasing of housing stock early in life and the flat portion later 


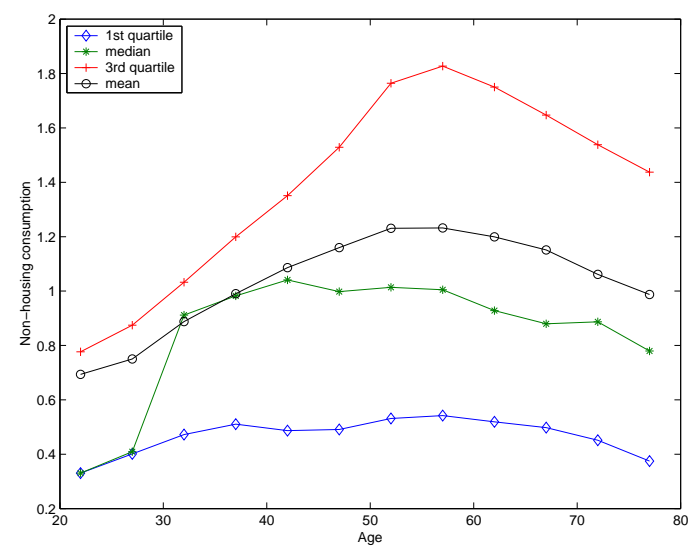

Figure 14: Non-housing consumption (quartiles)

in life at each quartile. The benchmark economy also generates the skewed distribution of housing consumption at each age group, as is observed in the data.

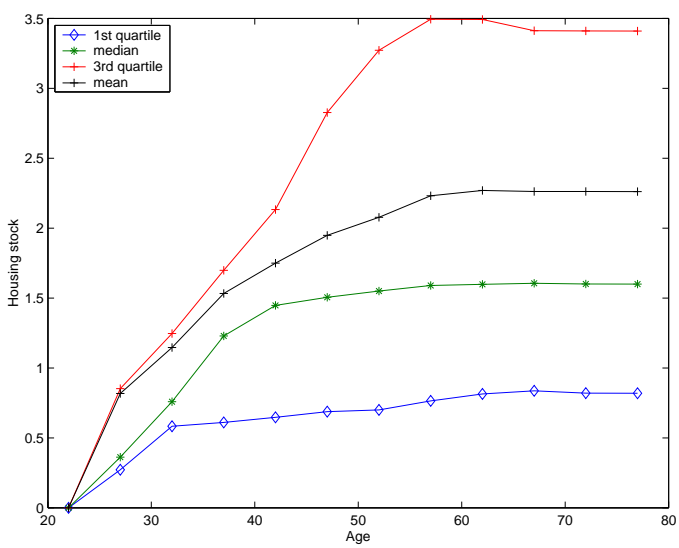

Figure 15: Housing consumption (quartiles)

The existence of transaction costs affects young agents and old agents differently. Young households face increasing income profiles and would like to purchase large houses but they have to accumulate enough non-housing assets to pay the down payment. As a result, they have to increase their housing stock fairly often. As the households age and their income profile stabilize, households would keep their level of housing stock unchanged, giving that trading of housing stock would incur transaction costs. Old households are less likely to move than young household, since they could only consume the new house for a relatively short period of time. Figure 16 shows the fraction of households moving at the end of each period for each age group. Moving rates by age in the data is taken from Schachter (2001) and are aggregated to five years. We see moving rates decline with age in the model, as in the data. Moving rates in the data is higher than in the model. One reason is that renters are also 


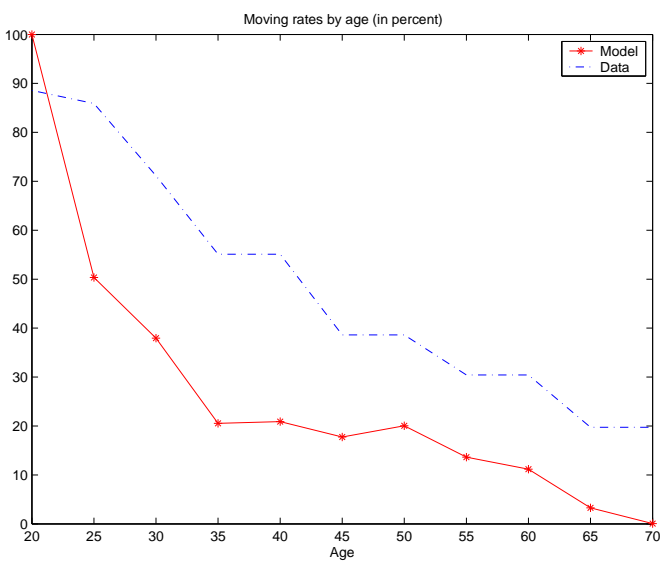

Figure 16: Moving rates by age

included in calculating the moving rates, and renters tend to move much more frequently than homeowners. The other reason is, households move for reasons other than income shocks and aging that this model abstracts from.

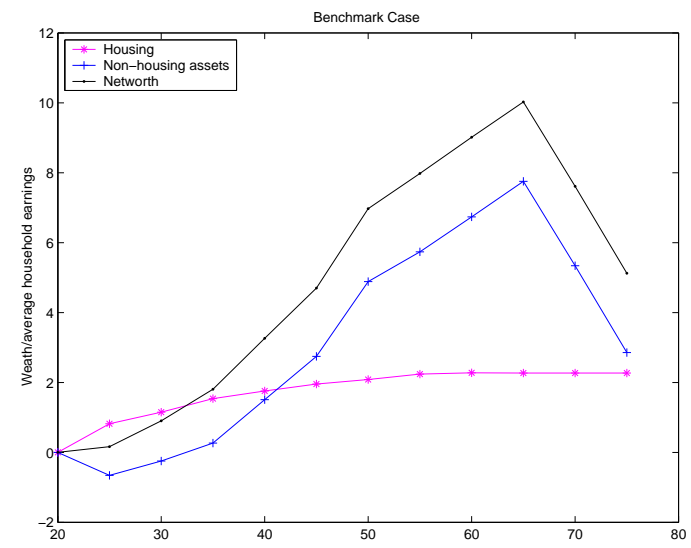

Figure 17: Life cycle patterns of wealth composition

Figure 17 displays the evolution of wealth portfolio over the life cycle. Young agents tend to hold little wealth. They start with zero wealth and they expect to have much higher earnings in the future. Thus to smooth consumption, they do not hold much wealth. Early in life households borrow as much as possible to buy houses, and thus save in the form of housing. As time goes by, agents have built stocks of houses and start to increase their holding of financial assets. The profile of financial assets and housing assets intersect in their early 40's, as is observed in the data. The wealth holding peaks at age 65 , the year before retirement. After retirement, they start to dissave assets to finance consumption. Old agents discount their future consumption at a higher rate since the survival probabilities are declining in age. This implies that the consumption profile is declining later in life and hence 
little wealth is needed to finance consumption later in life. Compared with data reported in Figure 8, the wealth profile and assets profile have humps that are more pronounced. Since I abstract from health expenditure uncertainty or other shocks that could motivate precautionary assets holding in old age, old agents do not have precautionary saving motives as they do in the data, therefore they run down their assets more quickly than in the data.

\subsection{Wealth distribution}

Table 3 reports values for the wealth distribution for my benchmark economy. I present quintile shares, the $90-95 \%$, the 95-99\%, the top 1\% shares and Gini coefficient for net worth, housing stocks and financial assets. US wealth distribution is calculated using $1998 \mathrm{SCF}$. In the data wealth is highly unevenly distributed with a Gini coefficient of 0.80 . The top $1 \%$ of the households hold $34 \%$ of the total wealth and the $95-99 \%$ of the households hold $24 \%$ of the total wealth. Housing is more evenly distributed than net worth with a Gini coefficient of 0.63 . The top $1 \%$ of the households hold $11 \%$ of the total housing wealth and the $95-99 \%$ of the households hold $17 \%$ of the total housing wealth. Financial asset is more unevenly distributed than net worth with a Gini coefficient of 0.99 . The top $1 \%$ of the households hold $46 \%$ of the total financial wealth and the $95-99 \%$ of the households hold $28 \%$ of the total financial wealth ${ }^{11}$.

The benchmark model matches the distribution of wealth, housing and financial wealth quite well, with the exception of top $1 \%$. It also replicates the empirical finding that inequality in financial assets is much higher than housing. This is because households are allowed to borrow against housing so financial assets can be negative but the housing stock can not be. Also for households that are not borrowing constrained, the return of housing, marginal utility of housing, is decreasing, while the return to financial assets, the interest rate, is constant. Thus housing as the fraction of net worth is decreasing.

\subsection{Bequest distribution}

Figure 18 compares the cumulative distribution of estate among the whole economy at any given time implied by the model with the data. The US data on the estate distribution is from Hurd and Smith (2001) who use the AHEAD data exit interview of 771 deceased between 1993-1995 ${ }^{12}$. The size distribution of the bequest is very concentrated both in the data and in the model: $30 \%$ of the deceased AHEAD respondents had an estate of no value ${ }^{13}$.

\footnotetext{
${ }^{11}$ All Gini coefficients are calculated without replacing the negative numbers with zeros. If I replace the negative numbers with zeros, then the Gini coefficients become slightly smaller

${ }^{12}$ I use distribution for single decedents. Using the bequest left by singles rather than the one for all decedents (which turns out to be 1-2 times bigger) is a more sensible choice because typically a surviving spouse inherits a large share of the estate, which will be partly consumed before finally being left to the couple's children.

${ }^{13} 30 \%$ households report leaving no bequest in AHEAD but $70 \%$ households report receiving no inheritance in SCF and PSID. One reason is that estates are often divided among several children.
} 


\begin{tabular}{|r|r|r|r|r|r|r|r|r|r|}
\hline & Gini & 1st & 2nd & 3rd & 4th & 5th & $90-95$ & $95-99$ & $99-100$ \\
\hline Total wealth \\
\hline U.S. data & 0.80 & -0.28 & 1.35 & 5.14 & 13.00 & 81.59 & 11.48 & 23.72 & 33.65 \\
\hline Model & 0.74 & 0.13 & 0.67 & 4.04 & 17.35 & 77.81 & 19.91 & 25.12 & 10.00 \\
\hline Housing \\
\hline US data & 0.63 & 0 & 1.09 & 13.66 & 24.10 & 61.15 & 13.87 & 17.12 & 11.32 \\
\hline Model & 0.48 & 1.73 & 8.39 & 14.71 & 24.59 & 50.58 & 13.02 & 11.79 & 3.74 \\
\hline Financial wealth \\
\hline US data & 0.99 & -6.00 & -0.12 & 1.26 & 7.23 & 97.64 & 11.98 & 28.20 & 46.35 \\
\hline Model & 0.86 & -6.07 & -2.68 & -0.29 & 12.32 & 96.71 & 24.51 & 33.70 & 14.07 \\
\hline
\end{tabular}

Table 3: Wealth distribution

The mean estate was $\$ 104,500$ but the median was much lower $(\$ 62,200)$. Some respondents leave relatively large estates: $30 \%$ are $\$ 120,000$ or more and $5 \%$ are in excess of $\$ 300,000$. Only $3 \%$ of the estates were valued at $\$ 600,000$ or more. One parameter of the model is chosen so that the two distributions match at one point: the 80th percentile. The estate distribution generated by the model actually matches very well to the AHEAD data until the 80 th percentile of the estate distribution. From that point on, the model predicts larger bequests than those observed in the AHEAD data. The discrepancy is partly due to the fact that AHEAD misses some large estates.

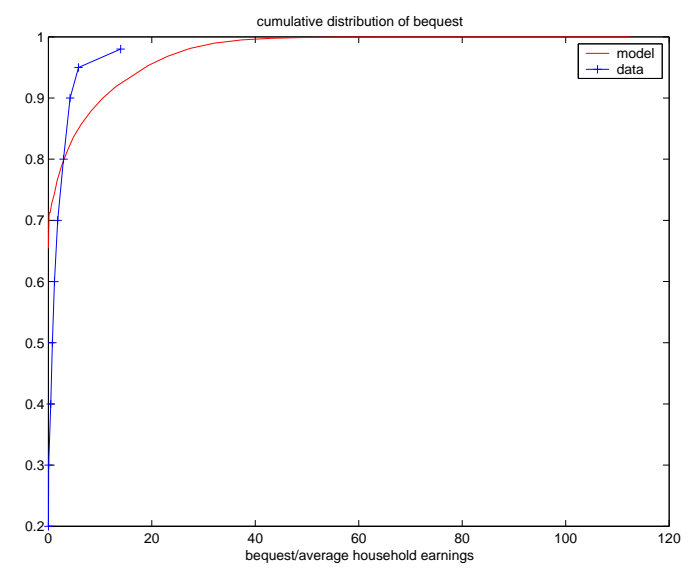

Figure 18: Cumulative distribution of bequest

Figure 19 shows the bequest distribution for a 35-year-old person conditional on his/her parent's observed productivity level. At that age, the probabilities of receiving bequests less than 2 times output per capita are, respectively, $71 \%, 19 \%, 1 \%$ and $0 \%$, for people with parents in the lowest, second lowest, second highest and highest productivity levels. Even in the presence of bequest motives, most of the parents run down their assets after retirement. 


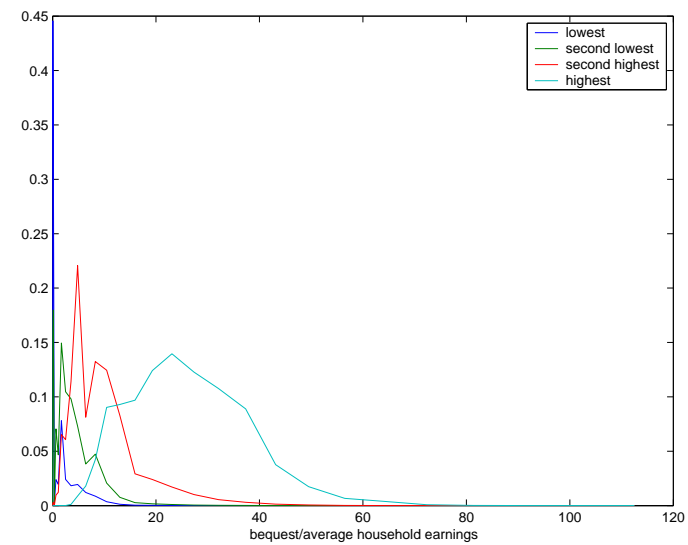

Figure 19: Expected bequest distribution at age 35, conditional on parent's productivity

The fraction of people whose parents live up to the final age of the model economy and who do not receive a positive bequest are, respectively, $99 \%, 98 \%, 88 \%$ and $23 \%$, for people with parents in the lowest, second lowest, second highest and highest productivity levels.

\section{Decomposition}

While the benchmark model does a good job in generating the different patterns of housing and non-housing consumption, and the evolution of assets composition, let us now try to understand how each ingredient affects the results. I change one parameter at a time, keeping other parameters as in the benchmark economy. This comparison can shed light on what role each feature of the model plays in generating the consumption and assets accumulation profiles.

First, I change the transaction costs. Then I change the remodeling-maintenance option. I further change parameters that govern the bequest motives. Then I check the effect of down payment ratio. I also change the elasticity of substitution between the housing and the non-housing consumption. Finally I study the effect of the pay-as-you-go social security system.

\subsection{Transaction cost}

Now I investigate the effects of transaction costs on household consumption and asset holding in this subsection by setting costs to 0. In Figure 20, we see the hump shape of the average non-housing consumption, which is similar to the one reported in the data and in the benchmark model. Compared with the benchmark case, a model without transaction costs generates a hump-shaped non-housing consumption profile but the decrease of housing stock later in life is too fast.

Figure 21 compares the ratio of housing to non-housing consumption in the model with 


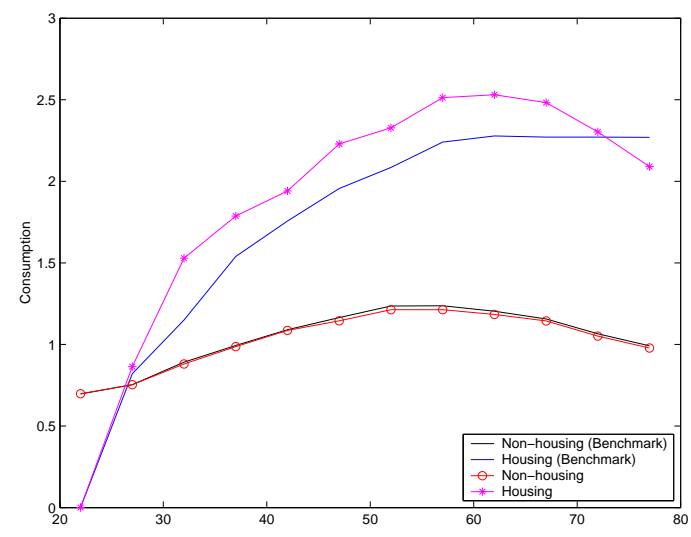

Figure 20: Life cycle patterns of consumption (no transaction costs: $\rho_{1}=\rho_{2}=0 \%$ )

and without transaction costs. Without transaction costs, the ratio becomes flatter over the life cycle. The ratio is increasing early in life because of the existence of borrowing constraints. Later in life when borrowing constraints are less likely to be binding, a model without transaction costs implies a flat pattern of the ratio of housing to non-housing consumption. These results show that borrowing constraints are essential in explaining the accumulation of housing assets early in life, while the transaction costs play an important role in explaining the slow decline of housing consumption later in life.

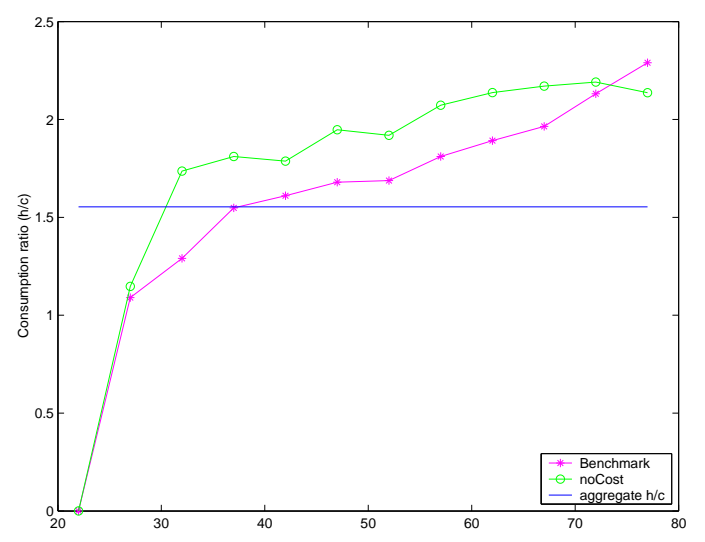

Figure 21: Ratio of housing to non-housing consumption (no transaction costs: $\rho_{1}=\rho_{2}=0 \%$ )

Figure 22 shows the average life cycle profiles of financial assets and total net worth. The evolution of the wealth portfolio over the life cycle is similar to the one in the benchmark case. The holding of financial assets is lower than the benchmark. This is because without transaction costs, housing assets become more attractive than financial assets. Therefore a household's portfolio shifts from financial assets to housing assets.

Figure 23 shows the effect of low transaction costs on average non-housing and housing consumption, when I set $\rho_{1}=3 \%$ and $\rho_{2}=1 \%$, half as in the benchmark economy. The 


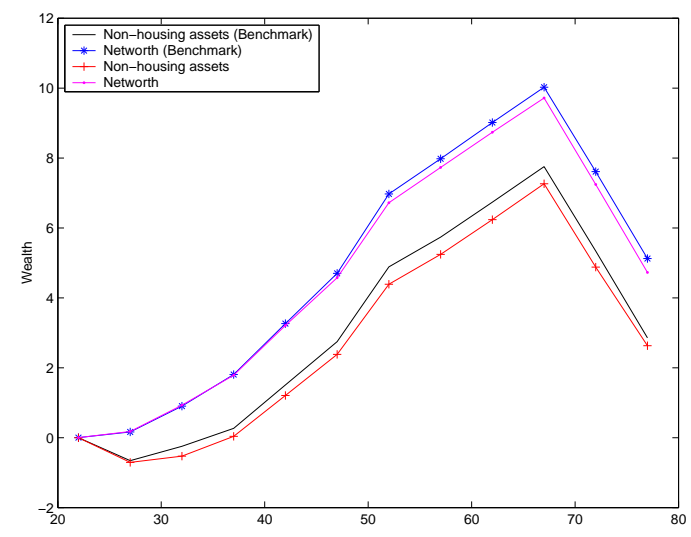

Figure 22: Life cycle patterns of wealth composition (no transaction costs: $\rho_{1}=\rho_{2}=0 \%$ )

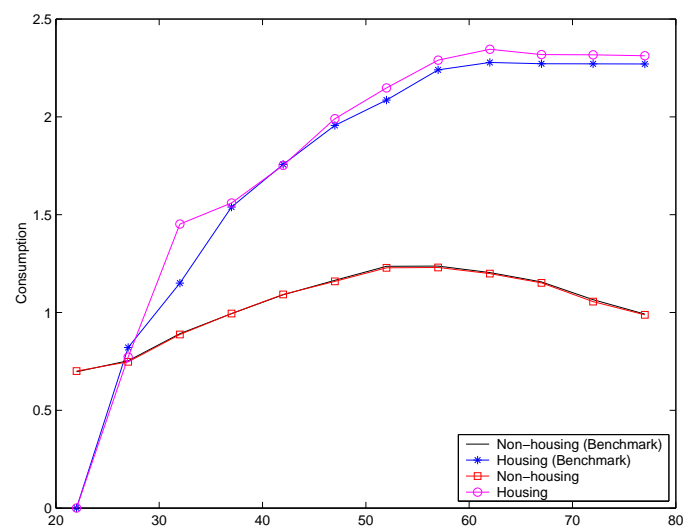

Figure 23: Life cycle patterns of consumption (high transaction costs: $\rho_{1}=3 \%$, $\rho_{2}=1 \%$ )

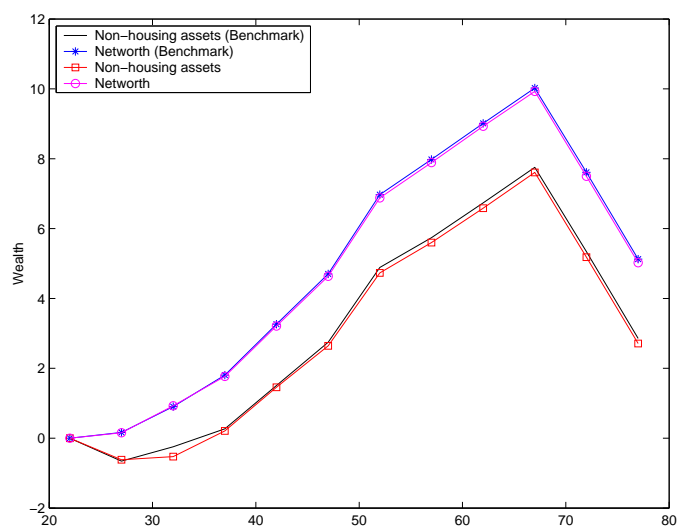

Figure 24: Life cycle patterns of wealth composition (high transaction costs: $\rho_{1}=$ $3 \%, \rho_{2}=1 \%$ )

housing consumption is higher than that in the benchmark. This is because when transaction costs are lower, housing assets become more attractive than financial assets. We also see that when the transaction costs are lower, housing consumption declines slightly after age 60. Figure 24 shows that the effect of low transaction costs on net worth profile is small.

Figure 25 shows the effect of high transaction costs on average non-housing and housing consumption, when I set $\rho_{1}=8 \%$ and $\rho_{2}=2 \%$. The housing consumption is lower than that in the benchmark. This is because when transaction costs are higher, housing assets become less attractive than financial assets. Figure 26 shows that the effect of high transaction costs on net worth profile is small.

\subsection{Remodeling-maintenance option}

Now I give agents the remodeling-maintenance option. I set $\mu_{1}=\mu_{2}=15 \%$ (which is equal to the depreciation rate in 5 years). That is to say, households are allowed to change their 


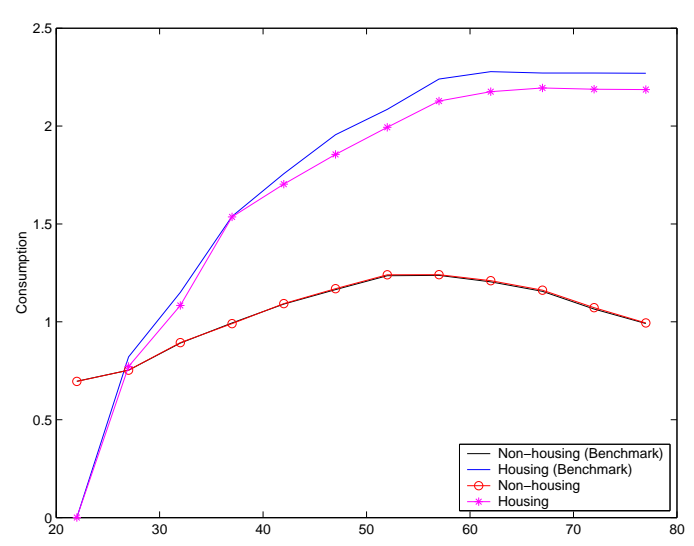

Figure 25: Life cycle patterns of consumption (high transaction costs: $\rho_{1}=8 \%$, $\rho_{2}=2 \%$ )

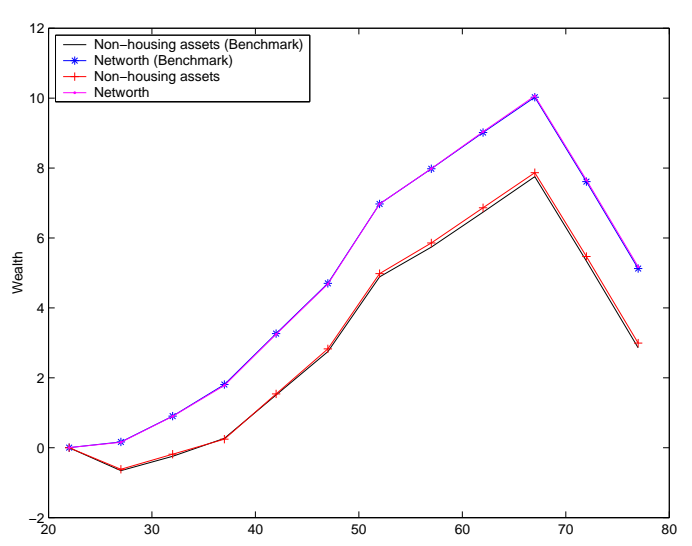

Figure 26: Life cycle patterns of wealth composition (high transaction costs: $\rho_{1}=$ $8 \%, \rho_{2}=2 \%$ )

level of housing consumption by allowing depreciation up to $15 \%$ the value of the house or by undertaking housing renovation up to a fraction of $15 \%$ the value of the house as an alternative to moving.

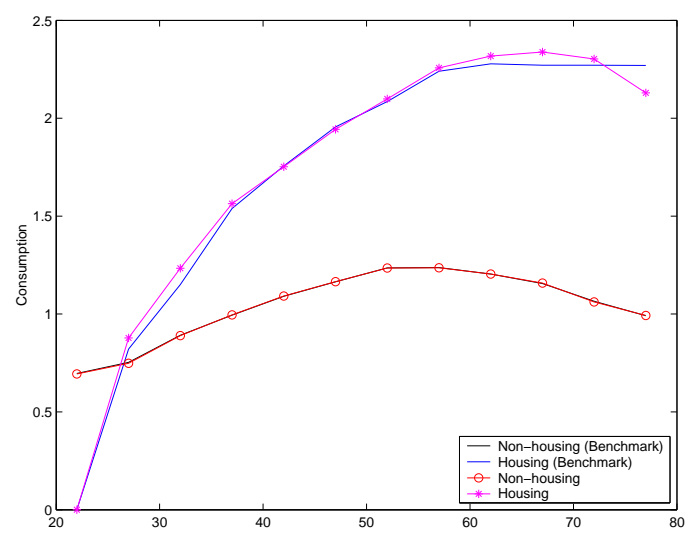

Figure 27: Life cycle patterns of consumption (remodeling-maintenance option: $\left.\mu_{1}=\mu_{2}=15 \%\right)$

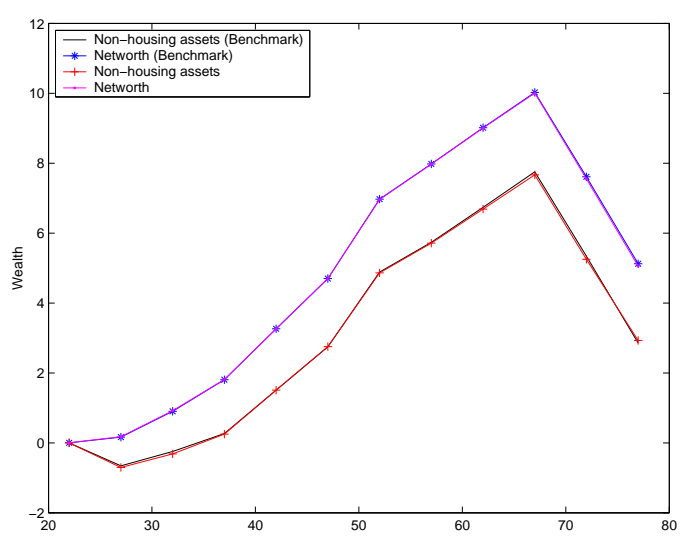

Figure 28: Life cycle patterns of wealth composition (remodeling-maintenance option: $\left.\mu_{1}=\mu_{2}=15 \%\right)$

From Figure 27, we see the same hump-shaped non-housing consumption profile. Housing stock is slightly higher than the benchmark model between age 25-35. This shows that most households would rather upsize their housing stock a lot therefore the remodelingmaintenance option has little effect. Only when at the last period, we see elderly households take the advantage of this option and allow the house to depreciate.

Figure 28 shows the average life cycle profiles of financial assets and total net worth. The evolution of the wealth portfolio over the life cycle is almost identical to the one in the benchmark case. 


\subsection{Bequest motive}

Now I present the results from a model without voluntary bequest motives by setting $\phi_{1}=0$. This modification removes a saving motive thus the aggregate capital stock and output are lower than in the benchmark economy. Figure 29 compares the average non-housing and housing consumption in the case of no bequest motives and in the benchmark case. Compared with the benchmark case, the profiles of housing and non-housing consumption have the similar shape, but the consumption of non-housing goods and housing is lower from age 45 and on. The reason is households are now receiving accidental bequest, which is much smaller than in the benchmark economy with bequest motives, therefore they have less resources to support consumption after middle age. The bequest motives are not the key factor explaining the slow downsizing of housing stock later in life for the average household. The intuition here is that the household faces transaction costs to downsize his/her housing stock, but can run down his/her financial assets without any costs. Without bequest motives, he/she chooses to run down his/her net worth completely by the time he/she expects to be dead for sure. Thus it is optimal to do so by running down his/her financial assets, rather than by trading the large house he/she lives in to a smaller one, and thus paying large transaction costs in the process ${ }^{14}$.

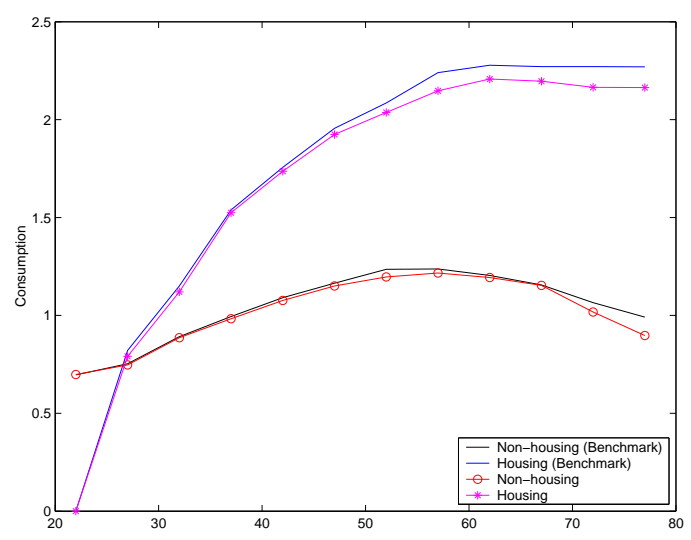

Figure 29: Life cycle patterns of consumption (no bequest motives: $\phi_{1}=0$ )

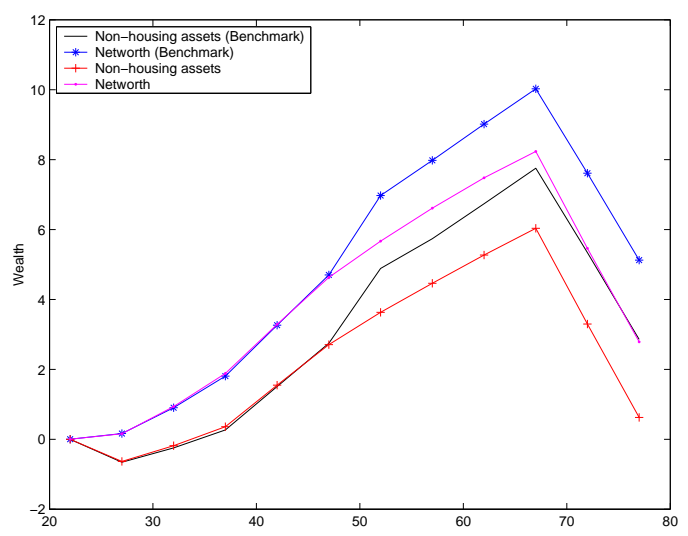

Figure 30: Life cycle patterns of wealth composition (no bequest motives: $\phi_{1}=0$ )

Figure 30 compares the average life cycle profiles of financial assets and total net worth in the case of no bequest motives and in the benchmark case. Compared with the benchmark case, the profiles of financial assets and total net worth is much lower from age 45 . The reason is that accidental bequest received is much smaller than in the benchmark economy. The bequest motives, therefore, play an important role in determining total life time wealth

\footnotetext{
${ }^{14}$ In the model, mortgages and deposits are perfect substitutes therefore the net mortgage position is indeterminant. The fact that households run down their financial assets does not necessary mean that households are borrowing against their houses using reverse mortgage products. The fraction of households aged 65 and above who hold wealth more than the value of the house are still pretty high, around $70 \%$ in the benchmark economy, and $67 \%$ in the case without bequest motive.
} 
and financial assets.

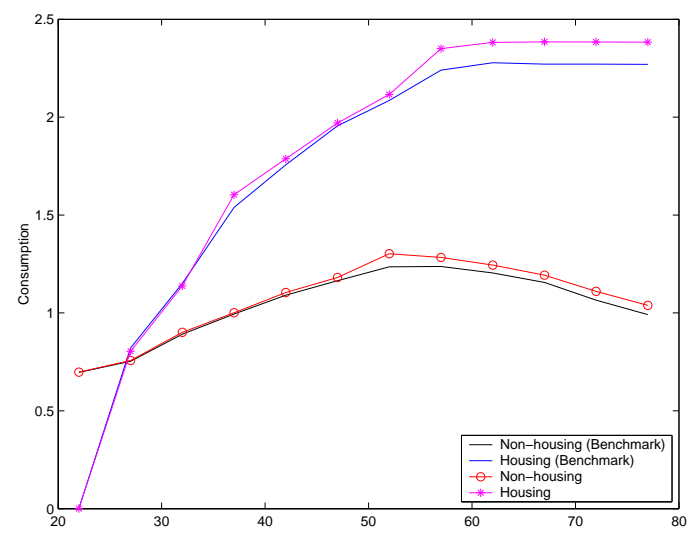

Figure 31: Life cycle patterns of consumption (high bequest motives: $\phi_{1}=-22$ )

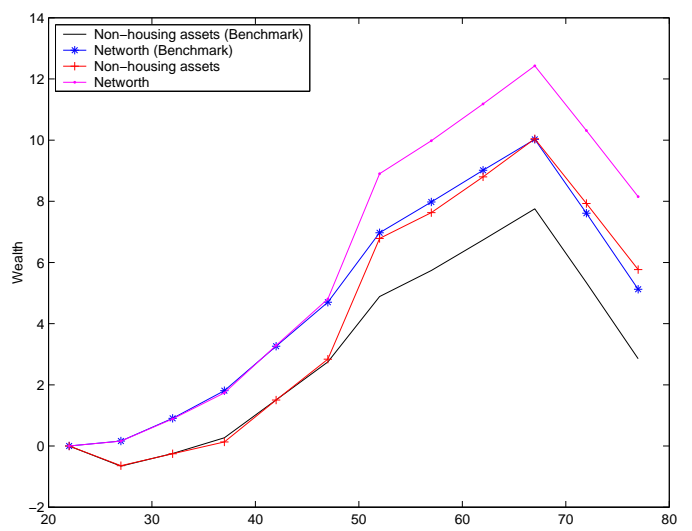

Figure 32: Life cycle patterns of wealth composition (high bequest motives: $\phi_{1}=-$ 22)

Since the bequest-output ratio reported in Gale and Scholz (1994) is a low estimate of the magnitude of the bequest motives, I present the results from a model with stronger voluntary bequest motives by setting $\phi_{1}=-22$. A stronger bequest motive increases the aggregate capital stock and output. Figures 31 and 32 show the average life cycle profiles of financial assets and total net worth, non-housing consumption and housing consumption. Compared with the benchmark case, the consumption of non-housing goods and housing is higher from age 45, the profiles of financial assets and total net worth is much higher from age 45 . The bequest motives, therefore, play an important role in determining total life time wealth and financial assets.

\subsection{Down payment}

Now I check the effect of the borrowing constraints on consumption paths and wealth paths by changing down payment ratio. The down payment ratio does affect the consumption of housing and non-housing when the households are young. If the down payment ratio is low, then young households are more likely to move into big houses, therefore the housing profile increases quickly. Figure 33 and Figure 34 show the average life cycle profiles of assets and consumption paths when the down payment ratio is 0. Compared with the benchmark, the consumption of housing goods is higher early in life. The profiles of wealth and consumption are similar to these in the benchmark economy for middle and old households, indicating that most of them are not constrained by the down payment requirement. Households use houses as collateral and they have negative financial wealth until their forties, a point at which they begin to save for retirement. This indicates that saving for purchasing houses is the main saving motive for young households.

On the contrary, when the down payment ratio is high, young households have to wait 


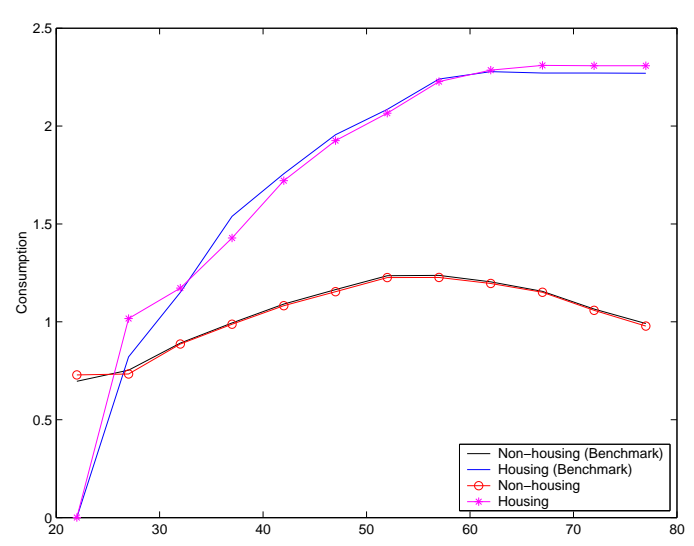

Figure 33: Life cycle patterns of consumption (no down payment: $\theta=0$ )

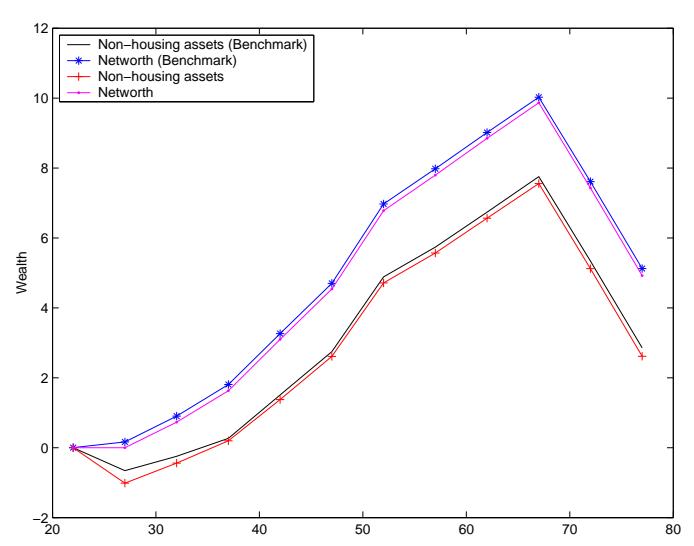

Figure 34: Life cycle patterns of wealth composition (no down payment: $\theta=0$ )

longer to accumulate more financial assets to pay higher down payments. Figure 35 and Figure 36 show the average life cycle profiles of assets and consumption paths when the down payment ratio is 0.4. Compared with the benchmark, the consumption of houses is lower early in life. Higher down payment ratio implies tighter borrowing constraints, therefore young households could not borrow as much as in the benchmark economy and have higher financial assets and higher net worth in this case.

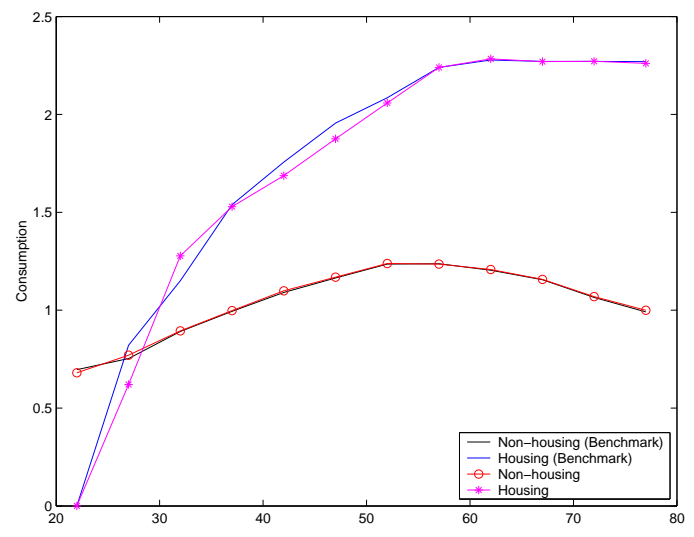

Figure 35: Life cycle patterns of consumption (high down payment: $\theta=0.4$ )

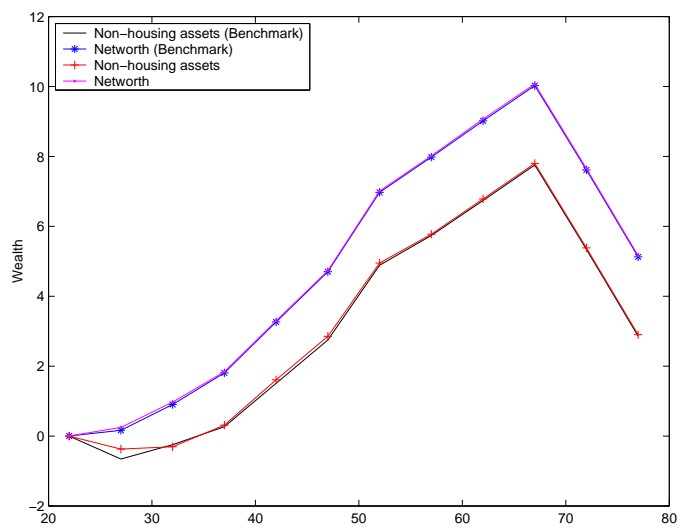

Figure 36: Life cycle patterns of wealth composition (high down payment: $\theta=0.4$ )

\subsection{Elasticity of substitution between housing and non-housing consump- tion}

In this subsection we will see the effect of the elasticity of substitution between the housing and non-housing consumption. Figure 37 and Figure 38 compare the average life cycle profiles of assets and consumption paths when the elasticity of substitution between the housing and non-housing consumption is $0.83(\sigma=-0.2)$ with the benchmark case. We still see the hump- 
shaped non-housing consumption and the non-hump-shaped housing consumption. Housing consumption is higher than in the benchmark. In the extreme case where housing and nonhousing are perfect complements $(\sigma=-\infty)$, agents would like to consume non-housing goods and housing goods in the same proportion therefore they accumulate housing assets faster. This explains why the accumulation of housing is faster when the elasticity is lower. Transaction costs for trading houses still prevent households from downsizing houses later in life, even when the elasticity is lower and households want to keep the consumption of housing and non-housing in the same proportion.

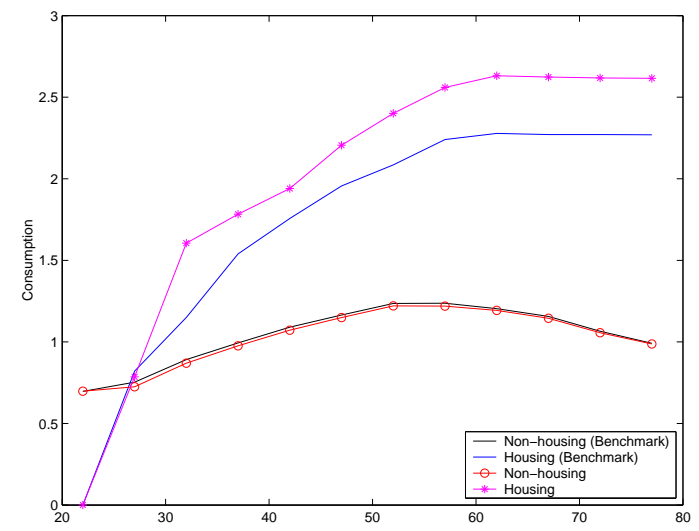

Figure 37: Life cycle patterns of consumption (low elasticity: $\sigma=-0.2$ )

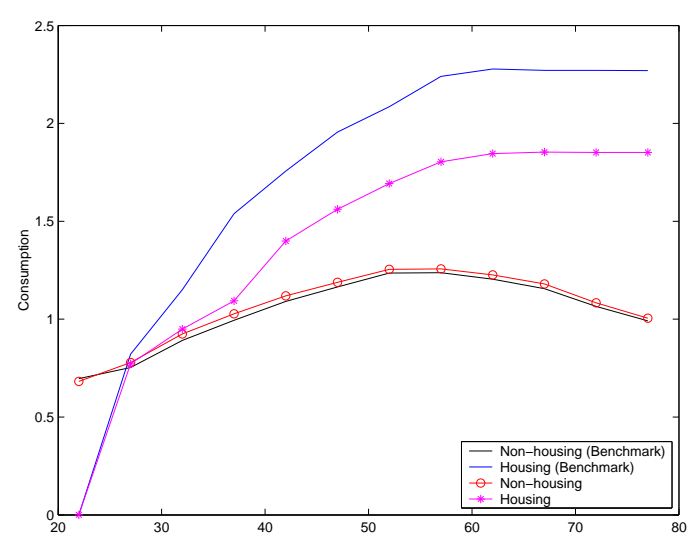

Figure 39: Life cycle patterns of consumption (high elasticity: $\sigma=0.2$ )

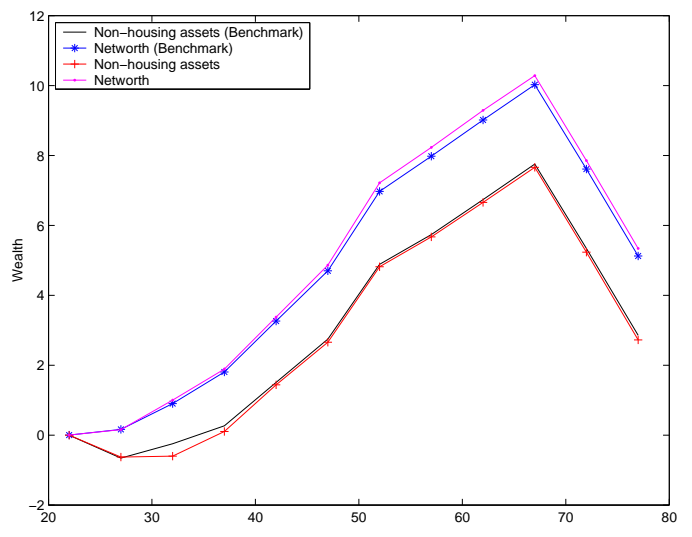

Figure 38: Life cycle patterns of wealth composition (low elasticity: $\sigma=-0.2$ )

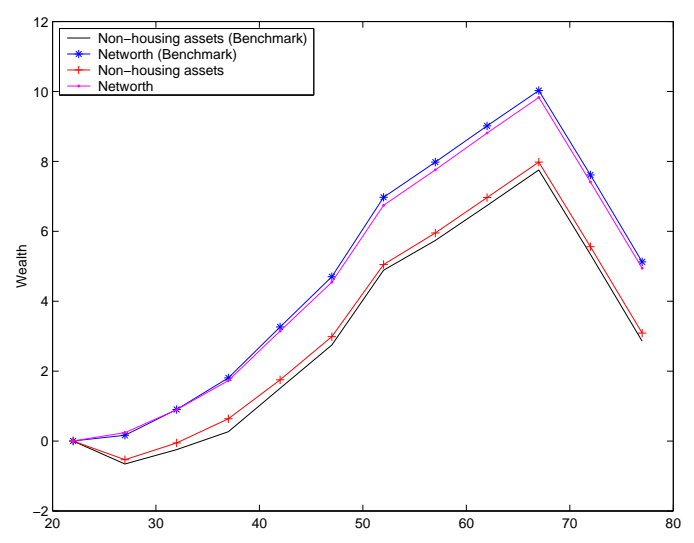

Figure 40: Life cycle patterns of wealth composition (high elasticity: $\sigma=0.2$ )

Figure 39 and Figure 40 compare the average life cycle profiles of assets and consumption paths when the elasticity of substitution between housing and non-housing is 1.25 ( $\sigma=$ 0.2 ) with the benchmark case. We still see the hump-shaped non-housing consumption and the non-hump-shaped housing consumption. When the elasticity of substitution is high, households could substitute more easily between non-housing and housing goods, thus they 
shift consumption from housing to non-housing. In the extreme case where housing and non-housing are perfect substitutes $(\sigma=1)$, agents will consume non-housing goods but no housing goods. This is because the net worth is bounded below by fraction $\theta$ of the value of houses, thus a bigger house implies a tighter borrowing constraint. This explains why the accumulation of housing is slower when the elasticity is high. When the elasticity of substitution is high, households are less willing to pay transaction costs to adjust housing consumption later in life. Thus transaction costs for trading houses prevent households from downsizing houses later in life.

\subsection{Pay-as-you-go social security system}

Now I look at an economy without a pay-as-you-go social security system. This modification strengthens saving for retirement, thus the aggregate capital stock and output are higher than in the benchmark economy. If I abandon a pay-as-you-go system in which the government taxes working agents and provides social security to retired agents, then young agents are less likely to be borrowing constrained, making the average non-housing and housing consumption increasing faster early in life. Also abandoning a pension system decreases the hump of wealth profile. Figure 41 shows the average life cycle profiles of consumption paths. We observe that the shapes of housing and non-housing consumption are similar as in the benchmark economy. The higher level of consumption is caused by the abandonment of social security tax which leaves agents more resources to consume.

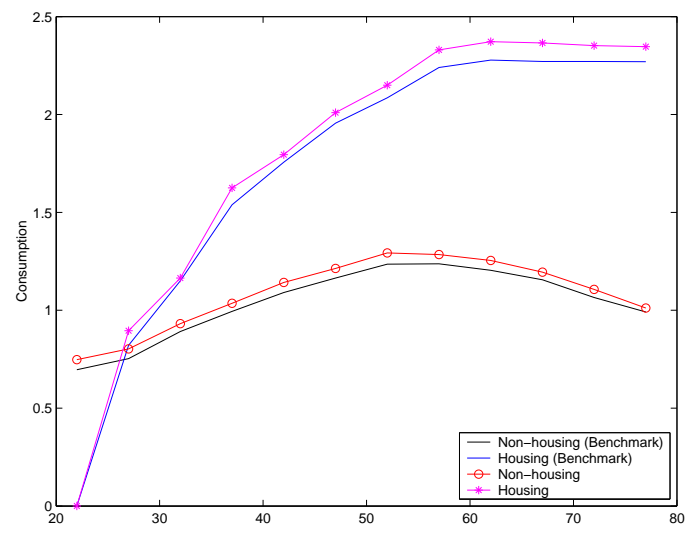

Figure 41: Life cycle patterns of consumption (no social security: $P=0$ )

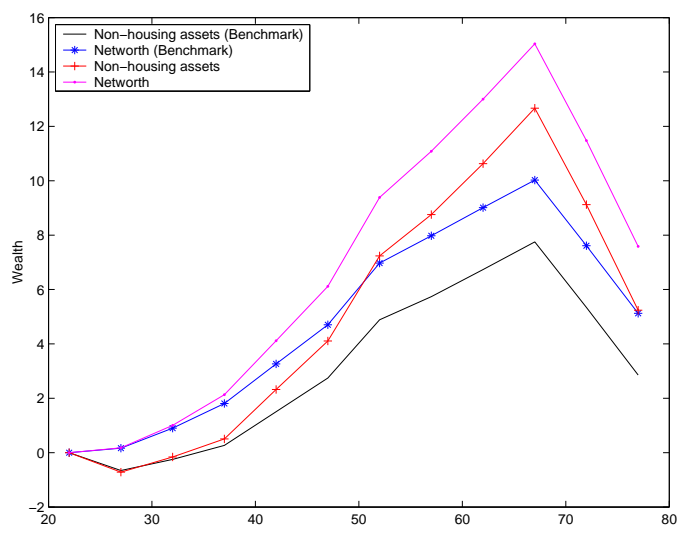

Figure 42: Life cycle patterns of wealth composition (no social security: $P=0$ )

Figure 42 shows the average life cycle profiles of assets when there is no pay-as-you-go social security system. Abandoning a social security system encourages private saving for retirement, thus wealth since the middle age, is much higher than in the benchmark case, and we see much more pronounced humps in wealth and financial asset profiles. 


\section{Conclusions}

This paper investigates the degree to which several modifications of the basic life cycle model produce consumption profiles of housing and non-housing that more closely resemble features of the US. To do this, I develop a quantitative and realistically calibrated dynamic general equilibrium model to solve numerically for the optimal housing and non-housing consumption decisions for a finitely-lived individual who faces several market frictions. One rational for using dynamic general equilibrium framework is that dynamic general equilibrium models are important tools for economic policy evaluation. Furthermore, in this dynamic general equilibrium framework, the time preference and the interest rate, which greatly affect the intertemporal consumption smoothing and thus the consumption profiles, can be jointly calibrated without having to match the consumption profiles.

The model is able to match two basic patterns observed in the data: the hump-shaped non-housing consumption profile and non-hump-shaped housing consumption profile. Households begin their economic lives without any housing stock. During the early part of their lives, they are forced to build housing stock and compromise on non-housing consumption. As households age, they start to decrease their non-housing consumption due to the fact that the time preference is higher than the interest rate and mortality rates are increasing along the life cycle. The high transaction costs for trading houses prevent households from decreasing their housing stock quickly later in life.

The model is also able to capture the life cycle wealth portfolio profiles. In the US, young households virtually own no liquid financial assets, but hold a major fraction of their wealth as housing. Later in life, households shift their portfolios to financial assets.

I also investigate the quantitative relevance of the transaction costs, borrowing constraints and bequest motives in determining this pattern. I find that while borrowing constraints are essential in explaining the accumulation of housing assets early in life, the existence of transaction costs is crucial in explaining the slow downsizing of housing profile later in life. The bequest motives play a role in determining total lifetime wealth, but not the housing profile.

In this paper I have abstracted from some important issues in order to make the model manageable and solvable. Now I discuss these simplifications and their likely quantitative implications.

One important assumption is that there are no inter-vivos transfers. In the data, parents tend to give children money when they need money the most, although data from Health and Retirement Study suggests that these transfers are fairly small (see Cardia and Ng (2000)). This assumption is probably relevant when agents are 20 to 35 years of age. Allowing for inter-vivos transfers would make young households have higher housing and non-housing consumption.

In order to simplify the computation, I do not adopt the literature using endogenous bor- 
rowing constraints. Fernandez-Villaverde and Krueger (2001) compare the life cycle profiles in a model with endogenous borrowing constraints with the exogenous constraints as in this model and they show that the life cycle profiles are identical across these two economies. The major difference between the two economies is that with endogenous borrowing constraints the net worth of the average young agents is slightly negative, indicating young agents are borrowing to finance the accumulation of housing and to smooth consumption over time and states. Since I focus on the consumption patterns later in life, I abstract from the endogeneity of borrowing constraints.

Another important assumption that I make is that there is no housing rental market. In the Survey of Income and Program Participation (SIPP), housing ownership for two-person households is low for young households and then increases to $75 \%$ at the age of 30 , staying flat and declining only slightly after age 75 (Venti and Wise (2004)). They find that in the absence of a shock, death of a spouse or entry of a family member into a nursing home, families are unlikely to discontinue home ownership. And even when there is a precipitating shock, discontinuing ownership is the exception rather than the rule. Thus the rental market is probably relevant for young households but less relevant for middle and old age households. I could incorporate a rental market into the framework to see if the results presented in this paper are robust to the existence of a rental market.

I assume that there is no cost of borrowing using housing as collateral. The fixed closing costs associated with refinancing a mortgage or applying for a second mortgage are estimated at 1.5 to 2.5 percent of the household's initial mortgage balance, although accessing home equity has become much easier in the 1990's relative to the 1980's (Bennett, Peach and Peristiani (2001)). Hurst and Stafford (2003) explore the use of equity as a mechanism by which households smooth their consumption over time and find that households with low income realizations are much more likely to refinance than households with medium or high income draws. Their analysis assumes households have fixed housing stock and focuses on the impact of temporary income shocks on refinancing decisions. It will be interesting to extend my model to look at the effect of income shocks on households moving decisions and refinancing decisions jointly.

I assume that the elderly do no face any health shocks. Even in the presence of social insurance (Medicare and Medicaid), households can face substantial out-of-pocket medical expenses (see French and Jones (2004), Palumbo(1999) and Feenberg and Skinner(1994)). Moreover nursing home expenses are potentially large and virtually uninsurable (Cohen, Tell and Wallack(1986)). The risk of incurring such medical expenses might generate precautionary savings and affect the wealth profile (De Nardi, French and Jones(2005)). The effect of medical costs on the life cycle consumption and saving in an environment with housing is left for future research. 


\section{Appendix}

\subsection{Consumption ratio in a standard life cycle model}

Given budget constraints, a household chooses $c_{t}, a_{t+1}, h_{t+1}$ to maximize its expected lifetime utility,

$$
\max _{c_{t}, a_{t+1}, h_{t+1}}\left\{\sum_{t=1}^{T} \beta^{t} E\left(s_{t-1} U\left(c_{t}, h_{t}\right)+\left(1-s_{t}\right) V\left(h_{t+1}+a_{t+1}\right)\right)\right\}
$$

subject to

$$
\begin{aligned}
c_{t}+a_{t+1}+h_{t+1} & =y_{t}+(1+r) a_{t}+\left(1-\delta^{h}\right) h_{t} \\
c_{t} & \geq 0, h_{t+1} \geq 0,
\end{aligned}
$$

where $c_{t}$ is consumption of non-housing assets at age $t, a_{t+1}$ is non-housing assets at age $t+1$, $h_{t+1}$ is housing stock at age $t+1, y_{t}$ is labor income at age $t$, which is stochastic, $s_{t}$ is the probability of surviving up to age $t$, where $s_{0}$ is $1, r$ is the interest rate, $\delta^{h}$ is depreciation rate of housing stock, $V$ is the utility from leaving bequest to their kids, while $V=0$ implies no bequest motives.

Theorem 1: The ratio of consumption of housing to non-housing goods should be ageindependent.

Proof of Theorem 1: Utility maximization implies that the following first order conditions hold:

$$
\left[a_{t+1}\right]: \quad \quad \beta^{t}\left(1-s_{t}\right) V^{\prime}\left(a_{t+1}+h_{t+1}\right)+(1+r) E_{t} \lambda_{t+1}=\lambda_{t}
$$

$$
\left[h_{t+1}\right]: \quad \beta^{t}\left(1-s_{t}\right) V^{\prime}\left(a_{t+1}+h_{t+1}\right)+\beta^{t+1} s_{t} E_{t} U_{2}\left(c_{t+1}, h_{t+1}\right)+\left(1-\delta^{h}\right) E_{t} \lambda_{t+1}=\lambda_{t} .
$$

Therefore from equation (17) and (18), we get

$$
\begin{aligned}
& \beta^{t+1} s_{t} E_{t} U_{2}\left(c_{t+1}, h_{t+1}\right)+\left(1-\delta^{h}\right) E_{t} \lambda_{t+1}=(1+r) E_{t} \lambda_{t+1}, \\
& \beta^{t+1} s_{t} E_{t} U_{2}\left(c_{t+1}, h_{t+1}\right)=\left(r+\delta^{h}\right) \beta^{t+1} s_{t} E_{t} U_{1}\left(c_{t+1}, h_{t+1}\right) .
\end{aligned}
$$


Which implies that

$$
\frac{E_{t} U_{2}\left(c_{t+1}, h_{t+1}\right)}{E_{t} U_{1}\left(c_{t+1}, h_{t+1}\right)}=\left(r+\delta^{h}\right)
$$

After retirement, households do not face income risk so equation (21) takes the deterministic form

$$
\frac{U_{2}\left(c_{t+1}, h_{t+1}\right)}{U_{1}\left(c_{t+1}, h_{t+1}\right)}=\left(r+\delta^{h}\right)
$$

If we assume

$$
\begin{aligned}
U(c, h) & =\frac{g(c, h)^{1-\eta}-1}{1-\eta} \\
g(c, h) & =\left(\omega(c)^{\sigma}+(1-\omega) h^{\sigma}\right)^{\frac{1}{\sigma}},
\end{aligned}
$$

then the ratio of housing to non-housing consumption is independent of age $t$,

$$
\frac{(1-\omega) h^{\sigma-1}}{\omega c^{\sigma-1}}=\left(r+\delta^{h}\right) .
$$

That is to say,

$$
\frac{h}{c}=\left(\frac{\left(r+\delta^{h}\right) \omega}{(1-\omega)}\right)^{\frac{1}{\sigma-1}} .
$$

The above model implies that the ratio of consumption of housing to non-housing goods should not be age-dependent. The implication of the above model is not consistent with the facts that later in life consumption of housing is flat while consumption of non-housing goods is declining.

\subsection{Definition of the stationary equilibrium}

I focus on an equilibrium concept where factor prices are constant over time and where capital and labor are constant in per capita terms. In addition, the age-wealth distribution is stationary over time. Each agent's state is denoted by $x$. An equilibrium is described as follows.

Definition 1 A stationary equilibrium is given by government policies $\tau_{l}, P$; an interest rate $r$ and a wage rate $w$; value functions $V(x)$, allocations $c(x), a^{\prime}(x), h^{\prime}(x)$; a family of probability distributions for bequests $\mu_{b}(x ;:)$ for a person with state $x$; and a constant distribution of people over the state variables $x: m^{*}(x)$, such that the following conditions hold:

(i) Given the government policies, the interest rate, the wage, and the expected bequest 
distribution, the functions $V(x), c(x), a^{\prime}(x)$, and $h^{\prime}(x)$ solve the above described maximization problem for a household with state variables $x$.

(ii) $m^{*}$ is the invariant distribution of households over the state variables for this economy. ${ }^{15}$

(iii) All markets clear.

$$
\begin{aligned}
K & =\int a m^{*}(d x), H=\int h m^{*}(d x), C=\int c m^{*}(d x), \\
L & =\int \epsilon y m^{*}(d x), T c=\int \tau\left(h^{\prime}, h\right) m^{*}(d x), \\
F(K ; L) & =C+(1+n) K-\left(1-\delta^{k}\right) K+(1+n) H-\left(\left(1-\delta^{h}\right) H-T c\right) .
\end{aligned}
$$

(iv) The price of each factor is equal to its marginal product.

$$
r=F_{1}(K, L)-\delta^{k}, w=F_{2}(K, L) .
$$

(v) The family of expected bequest distributions is consistent with the bequests that are actually left by the parents. ${ }^{16}$

(vi) Government budget is balanced at each period.

\subsection{Transition function}

From the policy rules and the exogenous Markov process for productivity, we can derive a transition function $\widetilde{M}(x ; \cdot)$, which is the probability distribution of $x^{\prime}$ (the state in the next period), conditional on $x$, for a person who behaves according to the policy rules $c(x), a^{\prime}(x)$ and $h^{\prime}(x)$. Let $\mathcal{P}$ be the cardinal set of $\{1, \ldots, T\}$ and $D$ indicates that a person is dead, and $\mathbb{W}=\left\{(a, h) \in \mathbb{R} \times \mathbb{R}_{+}: a \geq-(1-\theta) h\right\}$. The measurable space over which $\widetilde{M}$ is defined is $(\widetilde{X}, \mathfrak{B}(\widetilde{X}))$, with

$$
\begin{aligned}
X & =\{1, \ldots, T\} \times \mathbb{W} \times Y \times(Y \cup\{0\}) \\
\mathfrak{B}(X) & =\mathcal{P}(\{1, \ldots, T\}) \times \mathfrak{B}(\mathbb{W}) \times \mathfrak{B}(Y) \times \mathfrak{B}(Y \cup\{0\}) \\
\widetilde{X} & =X \cup D \\
\mathfrak{B}(\widetilde{X}) & =\{x: x=X \cup d, X \in \mathfrak{B}(X), d \in(\phi, D)\}),
\end{aligned}
$$

To characterize $\widetilde{M}$, it is enough to display it for the sets $L(\bar{t}, \bar{a}, \bar{h}, \bar{y}, \overline{y p})=\left\{\left(t^{\prime}, a^{\prime}, h^{\prime}, y^{\prime}, y p^{\prime}\right) \in\right.$

\footnotetext{
${ }^{15}$ I normalize $m^{*}$ so that $m^{*}(X)=1$, which implies that $m^{*}(\chi)$ is the fraction of people alive that are in a state $\chi$. Appendix 8.3 describes the calculation of invariant distribution in greater detail.

${ }^{16}$ Appendix 8.4 describes the consistency of bequest distribution in greater detail.
} 
$\left.X: t^{\prime} \leq \bar{t}, a^{\prime} \leq \bar{a}, h^{\prime} \leq \bar{h}, y^{\prime} \leq \bar{y}, y p^{\prime} \leq \overline{y p}\right\}$. On such sets $\widetilde{M}$ is defined by

$$
\begin{aligned}
& \widetilde{M}(x, L(\bar{t}, \bar{a}, \bar{h}, \bar{y}, \overline{y p})) \\
= & \left\{\begin{array}{cc}
p_{t} I_{t+1 \leq \bar{t}} Q_{y}(y,[0, \bar{y}] \cap Y) I_{h^{\prime}(x) \leq \bar{h}}\left\{I_{a^{\prime}(x) \leq \bar{a}}\left(I_{y p=0}+I_{y p \leq \overline{y p}} p_{t+6}\right)\right. \\
+\mu_{b}\left(x:\left[0, \bar{a}-a^{\prime}(x)\right]\left(1-p_{t+6}\right) I_{y p>0}\right\}, & \text { if } x \neq D \\
0, & \text { if } x=D,
\end{array}\right.
\end{aligned}
$$

where $I$ is an indicator function, which equals one if the subscript property is true and zero otherwise.

In the above equation, $p_{t}$ is the probability of surviving into the next period. The presence of $I_{t+1 \leq \bar{t}}$ shows that conditional on survival, a person currently of age $t$ will be of age $t+1$ next period. The person's evolution of productivity is described by $Q y$. Note that the evolution of productivity, a person's survival, and the survival of the person's parent are independent of each other. If the person's parent is already dead, that is, $y p=0$, the person cannot receive bequests anymore, and his or her assets next period are $a^{\prime}(x)$ for sure. (As discussed above, this is always the relevant case for people younger than 30 or older than 50.) If, instead, the parent is still alive, that is, $y p>0$, the parent can survive into the next period with probability $p_{t+6}$. In that case, tomorrow's assets for the person will be $a^{\prime}(x)$ and $y p^{\prime}=y p$. Alternatively, the parent may die, with probability $1-p_{t+6}$. In this case, the person inherits next period, $y p^{\prime}=0$, and the probability that next period's assets are no more than $\bar{a}$ is the probability of receiving a bequest between 0 and $\bar{a}-a^{\prime}(x)$. The last line shows that death is an absorbing state.

In the economy as a whole, I am not interested in keeping track of dead people, so I will define an operator on measures on $(X, \mathfrak{B}(X))$. Furthermore, I must take into account that new people enter the economy in each period. The transition function is defined as

$$
M(x, L(\bar{t}, \bar{a}, \bar{h}, \bar{y}, \overline{y p}))=\frac{\widetilde{M}(x, L(\bar{t}, \bar{a}, \bar{h}, \bar{y}, \overline{y p}))+n^{6} I_{t=6} Q_{y h}(y,[0, y] \cap Y) I_{y=y p^{\prime}}}{n} .
$$

The transition function $M$ differs from $\widetilde{M}$ in two ways. First, it accounts for population growth: when population grows at rate $n$, a group that is $1 \%$ of the population becomes $1 /(1+n) \%$ in the subsequent period. Second, it accounts for births, which explains the second term in the numerator. If a person is 50 years old $(t=7)$, that person's children (there are $(1+n)^{6}$ of them) will enter the economy next period. All of those children have age $t=1$ and zero assets and zero housing. Their stochastic productivity is inherited from their 50-year-old parents, according to the transition function $Q_{y h}$. $y$ is their parent's productivity at 50 .

Let $i^{*}$ be the invariant distribution of earnings at age 20 and parent's earnings at age 50 . 
The invariant distribution is defined recursively as following:

$$
\begin{gathered}
m^{*}(\{0\} \times \chi \times\{0\} \times\{0\})=i^{*}(\chi) \forall \chi \in \mathfrak{B}(Y) \times \mathfrak{B}(Y \cup\{0\}) \\
m^{*}(\{0\} \times \chi \times \mathbb{W} \backslash\{\{0\} \times\{0\}\})=0 \quad \forall \chi \in \mathfrak{B}(Y) \times \mathfrak{B}(Y \cup\{0\}) \\
m^{*}(\{t+1\} \times \chi)=\int M(x, \chi) m^{*}(\{t\} \times d x) \quad \forall t>1, \forall \chi \in \mathfrak{B}(\mathbb{W}) \times \mathfrak{B}(Y) \times \mathfrak{B}(Y \cup\{0\}) .
\end{gathered}
$$

\subsection{Consistency of bequest distributions}

I want to calculate the distribution $l(\cdot \mid t, y)$ of parents at age 50-80, conditional on the parent's productivity at age 50 and conditional on being alive. First I define $m_{t, y}^{*}$ as the marginal distribution of $x$ given age $t$ and productivity $y$ as

$$
m_{t, y}^{*}\left(\chi_{t, y}\right)=m^{*}\left(x \in X:(t, y) \in \chi_{t, y}\right) \quad \forall \chi_{t, y} \in \mathcal{P}(\{1, \ldots, T\}) \times \mathfrak{B}(Y) .
$$

Next I define $m^{*}(\cdot \mid t, y)$ as a probability distribution on $(X, \mathfrak{B}(X))$ for any given $(t, y)$. For any $\chi \in \mathfrak{B}(X), m^{*}(\cdot \mid t, y)$ is measurable with respect to $\mathcal{P}(\{1, \ldots, T\}) \times \mathfrak{B}(Y)$ and is such that

$$
\int_{\chi t, y} m^{*}(\cdot \mid t, y) m_{t, y}^{*}(d t, d y)=m^{*}(\chi) \forall \chi \in \mathfrak{B}(X) \forall \chi_{t, y} \in \mathcal{P}(\{1, \ldots, T\}) \times \mathfrak{B}(Y) .
$$

The children observe the parent's productivity at age 50. Therefore the conditional distribution of the parent at age 50 at productivity level $y_{p}$ is $m^{*}\left(\cdot \mid t=7, y=y_{p}\right)$. Therefore $l\left(\chi \mid t=7, y=y_{p}\right)=m^{*}\left(\chi \mid t=7, y=y_{p}\right)$ and recursively using the transition function $\widetilde{M}$ defined in the section above, we define

$$
l\left(\chi \mid t+1, y_{p}\right)=\frac{\int_{X} \widetilde{M}(x, \chi) l\left(d x \mid t, y_{p}\right)}{p_{t}} .
$$

Since the bequest is evenly distributed among children, the probability distributions for bequests $\mu_{b}(x ;:)$ for a person with state $x=(t, a, h, y, y p)$ is given by

$$
\begin{aligned}
\mu_{b}(x & : \quad \chi)=l\left(a \in \mathbb{R}_{+}, h \in \mathbb{R}_{+}:\left((1+n)^{6} a+(1+n)^{6}\left(h\left(1-\rho_{1}\right)\right) \in \chi \mid t+6, y_{p}\right)\right. \\
\forall \chi & \in \mathfrak{B}\left(\mathbb{R}_{+}\right), \forall a, h \in \mathbb{W} \forall y, y p \in \mathfrak{B}(Y) .
\end{aligned}
$$

\subsection{Calibration}

I calibrate my model following Cooley and Prescott (1995) and Diaz and Luengo-Prado (2003). I use data from the National Income and Product Accounts and the Fixed Assets Tables published by the Bureau of Economic Analysis for the year 1959-2001. In order to 
properly calibrate a model with two assets and without government taxes and expenditures, I make some imputations.

I define measured GDP as the sum of each final expenditures:

$$
G D P=\left(c+s h+i_{c d}+c_{g}\right)+\left(i_{p r k}+i_{p n r k}+i_{g}\right)+n x+\triangle i n v
$$

where $c, s h, i_{c d}$ and $c_{g}$ are expenditures on non-housing and service excluding housing, housing services, expenditures on consumer durables, government consumption expenditures, respectively. Thus $c+s h+i_{c d}+c_{g}$ are total consumption expenditure. $i_{p r k}, i_{p n r k}$ and $i_{g}$ are total private residential investment, nonresidential investment and government investment, respectively. Thus $i_{p r k}+i_{p n r k}+i_{g}$ are total investment.

I also write GDP as the sum of wages plus rents of residential and nonresidential stocks of capital:

$$
G D P=w e+p r k \cdot r_{p r k}+p n r k \cdot r_{p n r k} .
$$

To explicitly consider the existence of residential housing I rearrange output as

$$
G D P=\left(c+i_{c d}+c_{g}\right)+s h+i_{p r k}+\left(i_{p n r k}+i_{g}+n x+\triangle i n v\right) .
$$

Since there is no rental market in this model, I subtract rental income from residential housing from GDP.

$$
\begin{aligned}
Y & =w e+p n r k \cdot r_{\text {pnrk }}=G D P-s h \\
K & =p n r k+i n v+g \\
H & =p r k \\
i_{h} & =i_{p r k},
\end{aligned}
$$

where $K$ includes private fixed non-residential assets and government fixed non-residential assets, $H$ includes private fixed residential assets and government fixed residential assets. Both measures are taken from the Fixed Assets Tables.

Following Cooley and Prescott (1995), I define unambiguous capital income (UCI) as rental income, corporate profits and net interest, and define ambiguous capital income (ACI) as other income excluding wage and depreciation. Thus capital income $Y_{k}$ is defined as $\mathrm{UCI}+\alpha \cdot \mathrm{ACI}+$ depreciation-sh $=\alpha \cdot Y$. Subtracting housing from output, the share of capital is calibrated as

$$
\alpha=(U C I+\operatorname{dep}-s h) /(Y-A C I) .
$$

I compute an average share of capital $\alpha=0.2261$, an average capital-output ratio $\frac{K}{Y}=$ 1.9887, an investment-capital ratio $\frac{i_{k}}{k}=0.082$, a housing stock to output ratio $\frac{H}{Y}=1.2141$, 
an investment-housing stock ratio $\frac{i_{h}}{H}=0.041$ and a non-housing to housing investment ratio $\frac{C}{i_{h}}=15.9443$. The implied depreciation rates is $\delta^{k}=\frac{i_{k}}{k}-n=0.07, \delta^{h}=\frac{i_{h}}{H}-n=0.0294$, interest rate net of depreciation in a steady state is $r=\alpha \frac{Y}{K}-\delta^{k}=4.37 \%$.

\subsection{Computation of the model}

Since I introduce the non-convex transaction costs on housing, I could not use Euler equation approximation or policy function iteration. Hence I solve the model using approximation of value functions.

To compute the steady state of my model, I first discretize income process and income inheritance process following Tauchen and Hussey (1991). The state space for housing and asset holdings are discretized. The upper bounds on the grids are chosen large enough so that they do not constitute a constraint on the optimization problem. Using these grids I can store the value functions and the distribution of households as finite-dimensional arrays.

I solve the approximated optimal consumption and saving plans recursively. Households surviving to the last period $T$ has an easy problem to solve. Based on the period $T$ policy functions, I solve the consumption and saving decisions that maximize the period $T-1$ value function. The same procedure is carried back until decision rules in the first period are computed for a large number of states.

I solve for the steady state equilibrium as follows:

1. Given an initial guess of interest rate $r$, use the equilibrium conditions in the factor markets to obtain the wage rate $w$.

2. Set the interval for housing and assets.

3. Guess an initial bequest distribution.

4. Set value function after the last period to be 0 and solve the value function for the last period of life for each of the points of the grid. This yields policy functions and value function at the last period.

5. By backward induction, repeat step 4 until the first period in life.

6. Compute the associated stationary distribution of households by forward induction using the policy functions starting from the known distribution over types of age.

7. Given the stationary distribution and policy functions, compute the bequest distribution. If the bequest distributions converges, go to step 8; otherwise go to step 3.

8. Check if the distributions of housing and assets do not have a large mass at the maximum levels. If so, increase the maximum level and go back to step 2. If not, continue to step 9 .

9. Given the stationary distribution and prices, compute factor input demands and supplies and check market clearing conditions hold. If all markets clear, an equilibrium is found. If not, go to step 1 and update interest rate $r$. 


\section{References}

[1] Alessie, Rob, Michael P. Devereux, and Guglielmo Weber, "Intertemporal Consumption, Durables and Liquidity Constraints: A Cohort Analysis," European Economic Review, 41 (1997), 37-59.

[2] Altonji, Joseph G., and Ernesto Villanueva, "The Effect of Parental Income on Wealth and Bequests," NBER working paper No. 9811, 2002.

[3] Atkinson, Anthony, Lee Rainwater and Timothy Smeeding, "Income Distribution in OECD Countries: Evidence from the Luxembourg Income Study (LIS)," Social Policy Studies, 18 (1995), Paris, OECD.

[4] Attanasio, Orazio, James Banks, Costas Meghir and Guglielmo Weber, "Humps and Bumps in Lifetime Consumption," Journal of Business and Economics, 17 (1999), 2235.

[5] — Erich Battistin and Hidehiko Ichimura, "What Really Happened to Consumption Inequality in the US?" NBER Working Paper No. 10338, 2004.

[6] - Pinelopi K. Goldberg and Ekaterini Kyriazidou, "Credit Constraints in the Market for Consumer Durables: Evidence from Micro Data on Car Loans," NBER Working Paper No. 7694, 2000.

[7] - and Guglielmo Weber, "Is Consumption Growth Consistent with Intertemporal Optimization? Evidence for the Consumer Expenditure Survey," Journal of Political Economy 103 (1995), 1121-1157.

[8] Beaulieu, Joseph J., "Optimal Durable and Nondurable Consumption with Transactions Costs," Federal Reserve Board Finance and Economics Discussion Series, April 1993.

[9] Bell, Felicitie C., Alice H. Wade and Stephen C. Goss, "Life Tables for the United States Social Security Area 1900-2080," Actuarial Study No. 107, US Department of Health and Human Services, Social Security Administration, Office of the Actuary, August 1992.

[10] Bennett, Paul, Richard Peach and Stavros Peristiani, "Structural Changing in the Mortgage Market and the Propensity to Refinance," Journal of Money, Credit and Banking, 33 (2001), 955-75.

[11] Blundell, Richard, Martin Browning and Costas Meghir, "Consumer Demand and the Life-Cycle Allocation of Household Expenditures," Review of Economic Studies, 61 (1994), 57-80.

[12] Browning, Martin, and Mette Ejrnæs, "Consumption and Children," Centre for Applied Microeconometrics Working Paper, 2002. 
[13] Brugiavini, Agar, and Guglielmo Weber, "Durable and Nondurable Consumption: Evidence from Italian Household Data," IFS Working Paper 92/13, 1992.

[14] Buhmann, Brigitte, Lee Rainwater, Guenther Schmaus, and Timothy M. Smeeding, "Equivalence Scales, Well-Being, Inequality and Poverty: Sensitivity Estimates across Ten Countries Using the Luxembourg Income Study Database," Review of Income and Wealth, 34 (1988), 115-142.

[15] Bullard, James and James Feigenbaum, "A Leisurely Reading of the Lifecycle Consumption Data," Working Paper, 2004.

[16] Campbell, John Y., and Joao F. Cocco, "Household Risk Management and Optimal Mortgage Choice," Quarterly Journal of Economics, 118 (2003), 1149-1194.

[17] Caplin, Andrew, Sewin Chan, Charles Freeman and Joseph Tracy, Housing Partnerships: A New Approach to a Market at a Crossroads (Cambridge: MIT Press, 1997).

[18] Cardia, Emanuela, and Serena Ng, "How Important are Intergenerational Transfers of Time? A Macroeconomic Analysis," Working paper, 2000.

[19] Carroll, Christopher D., "Buffer-Stock Saving and the Life-Cycle/Permanent Income Hypothesis," Quarterly Journal of Economics, 112 (1997), 1-55.

[20] - and Lawrence H. Summers, "Consumption Growth Parallels Income Growth: Some New Evidence," in B. Douglas Bernheim and Jonh Shoven eds. National Saving and Economic Performance (Chicago: University of Chicago Press, 1991).

[21] Chah, Eun, Valerie Ramey and Ross Starr, "Liquidity Constraints and Intertemporal Consumer Optimization: Theory and Evidence from Housing," Journal of Money, Credit and Banking 27 (1995), 272-287.

[22] Chinloy, Peter, "An Empirical Model of the Market for Resale Homes," Journal of Urban Economics, 7 (1980), 279-292.

[23] Cocco, Joao, "Portfolio Choice in the Presence of Housing," Review of Financial Studies, $18(2005), 535$.

[24] Cohen, Marc, Eileen J. Tell and Stanley J. Wallack, "The Lifetime Risks and Costs of Nursing Home Use among the Elderly," Medical Care, 24 (1986), 1161-1172.

[25] Cooley, Thomas F., and Edward Prescott, "Economic Growth and Business Cycles," In Thomas F. Cooley eds., Frontiers of Business Cycle Research (Princeton: Princeton University Press, 1995), 1-38.

[26] De Nardi, Mariacristina, "Wealth Inequality and Intergeneration Links," Review of Economic Studies, 71 (2004), 734-768. 
[27] — Eric French and John B. Jones, "Differential Mortality, Uncertain Medical Expenses, and the Saving of Elderly Singles," Federal Reserve Bank of Chicago working paper no.13, 2005.

[28] Diaz, Antonia, and Maria J. Luengo-Prado, "Precautionary Saving and Wealth Distribution with Housing," Working paper, 2003.

[29] Eberly, Janice, "Adjustment of Consumers Durables Stocks: Evidence from Automobile Purchases," Journal of Political Economy, 106 (1994), 403-436.

[30] Engelhardt, Gary, "House Prices and Home Owner Saving Behavior," Regional Science and Urban Economics, 26 (1996), 313-336.

[31] Feenberg, Daniel, and Jonathan Skinner, "The Risk and Duration of Catastrophic Health Care Expenditures," Review of Economics and Statistics, 76 (1994), 633-647.

[32] Fernandez-Villaverde, Jesus, and Dirk Krueger, "Consumption and Saving over the Life Cycle: How Important are Consumer durables?" Proceedings of the 2002 North American Summer Meetings of the Econometric Society, 2001.

[33] — and - "Consumption over the Life Cycle: Some Facts from Consumer Expenditure Survey Data," NBER Working Paper No. 9382, 2002.

[34] Flavin, Marjorie and Shinobu Nakagawa, "A Model of Housing in the Present of Adjustment Costs: a Structural Interpretation of Habit Persistence," NBER Working Paper No. 10458, 2004.

[35] — and Takashi Yamashita, "Owner-Occupied Housing and the Composition of the Household Portfolio," American Economic Review, 92 (2002), No. 1, 345-362.

[36] French, Eric, and John B. Jones, "On the Distribution and Dynamics of Health Care Costs," Journal of Applied Econometrics, 19 (2004), 705-721.

[37] Gale, William, and John K. Scholz, "Intergenerational Transfers and the Accumulation of Wealth," Journal of Economic Perspectives, 8 (1994), 145-160.

[38] Gourinchas, Pierre-Olivier, and Jonathan A. Parker, "Consumption over the Life Cycle," Econometrica, 70 (2002), 47-89.

[39] Grossman, Sanford, and Guy Laroque, "Asset Pricing and Optimal Portfolio Choice in the Presence of Illiquid Housing Consumption Goods," Econometrica, 58 (1990), 25-51.

[40] Gruber, Joseph, and Robert F. Martin, "The Role of Durable Goods in the Distribution of Wealth: Does Housing Make Us Less Equal?" Working Paper, 2003. 
[41] Hansen, Gary D., "The Cyclical and Secular Behavior of the Labor Input: Comparing Efficiency Units and Hours Worked," Journal of Applied Econometrics, 8 (1993), 71-80.

[42] — , and Selahattin Imrohoroglu, "Consumption over the Life Cycle: The Role of Annuities, " Working Paper, 2005.

[43] Heathcote, Jonathan, "Home Production and Retirement," Working Paper, 2002.

[44] Hendricks, Lutz, "Bequests and Retirement Wealth in the United States," Working Paper, 2001.

[45] Hubbard, R. Glenn, Jonathan Skinner and Stephen P. Zeldes, "The Importance of Precautionary Motives in Explaining Individual and Aggregate Saving," Carnegie-Rochester Conference Series on Public Policy 40 (1994), 59-126.

[46] Hurd, Michael, and James P. Smith, "Anticipated and Actual Bequests", Themes in the Economics of Aging, David Wise, editor, 2001, Chicago: University of Chicago Press, 357-389.

[47] Hurst, Erik, and Frank Stafford, "Home is Where the Equity is: Mortgage Refinancing and Household Consumption," Working Paper, 2003.

[48] Jappelli, Tullio, "Who is Credit Constrained in the US Economy?" Quarterly Journal of Economics, 105 (1990), 219-234.

[49] Johnson, David S., and Thesia I. Garner, "Unique Equivalence Scales: Estimation and Implications for Distributional Analysis," Journal of Income Distribution, 4 (1995), 215234.

[50] — and Timothy M. Smeeding, "Intergenerational Equity in the United States: the Changing Well-being of the Old and the Young, 1960-1995," Bureau of Labor Statistics Working Paper, 1998.

[51] Laitner, John, "Wealth Accumulation in the US: Do Inheritance and Bequests Play a significant Role?" Working paper, 2001.

[52] Martin, Robert F., "Consumption, Housing and Transaction Costs," Board of Governors Federal Reserve System International Finance Discussion Paper No 756, 2003.

[53] Nelson, Julie, "Household Economics of Scale in Consumption: Theory and Evidence," Econometrica 56 (1988) 1301-1304.

[54] Ocampo, Ignacio, and Kazuhiro Yuki, "Saving, Intergenerational Transfers, and the Distribution of Wealth," Working Paper, 2002. 
[55] Ogaki, Masao, and Carmen M. Reinhart, "Measuring Intertemporal Substitution: The Role of Durable Goods," Journal of Political Economy, 106 (1998), 1078-1098.

[56] Ortalo-Magne, François, and Sven Rady, "Housing Market Dynamics: on the Contribution of Income Shocks and Credit Constraints," Review of Economic Studies, 73 (2006), 459-485.

[57] Palumbo, Michael, "Uncertain Medical Expenses and Precautionary Saving Near the End of the Life Cycle," Review of Economic Studies, 66 (1999), 395-421.

[58] Schachter, Jason, "Geographical Mobility: March 1999 to March 2000," US Census Bureau, 2001.

[59] Smith, Lawrence B., Kenneth T. Rosen, and George Fallis, "Recent Developments in Economic Models of Housing Markets," Journal of Economic Literature, 26 (1988), 2964.

[60] Tauchen, George, and Robert Hussey, "Quadrature-Based Methods for Obtaining Approximate Solutions to Nonlinear Asset Pricing Models," Econometrica, 59 (1991), 371396.

[61] Yang, Fang, "How Do Households Portfolio Vary with Age?" Working Paper, 2006.

[62] Yao, Rui, and Harold. H. Zhang, "Optimal Consumption and Portfolio Choices with Risky Housing and Borrowing Constraint," Review of Financial Studies, 18 (2005), 197239.

[63] Zeldes, Stephen, "Consumption and Liquidity Constraints: An Empirical Investigation," Journal of Political Economy 97 (1989), 305-346.

[64] Zimmerman, David J., "Regression Toward Mediocrity in Economic Stature," American Economic Review, 82 (1992), 409-429. 